\title{
The Challenge of Cleaning Woven Filter Cloth in the Beverage Industry-Wash Jets as an Appropriate Solution
}

\author{
Roman Alejandro Werner ${ }^{1}$ (D) Dominik Ulrich Geier ${ }^{1} \cdot$ Thomas Becker $^{1}$
}

Received: 1 August 2019 / Accepted: 22 May 2020 / Published online: 24 July 2020

(C) The Author(s) 2020

\begin{abstract}
Beverage production requires many different and complex unit operations. One crucial procedural step is filtration. Typical filters are filter presses, candle filters, membrane filters, belt filters, and drum filters, which require considerable hygienic precaution and the application of appropriate cleaning concepts. In the last decades, the hygienic design has become a central design feature of equipment in the beverage and food industries. Today, also correspondent concepts regarding filter cloth increasingly come to the fore. However, filter cloth cleaning is rapidly facing limitations. Complex filter geometries originating from different gauzes and sensitive polymeric materials hinder efficient cleaning. Additionally, extensive biological residues adhering to the filter surface increase the challenge of cleaning. The goal of this paper is to outline the cleaning of woven filter cloths systematically with a particular focus on beverages and correspondent biophysical interactions between filter and residue. Based on these elemental cleaning limits of filter cloths, this paper focuses mainly on jet cleaning as one of the most appropriate cleaning methods. The flow-mechanical properties are discussed in detail since these are precisely the parameters that, on the one hand, describe the understanding of the cleaning process and, on the other hand, show how a wash jet can be adjusted precisely. In contrast to conventional cleaning techniques, such wash jets are expeditious to adapt and offer the best prerequisites to enable demandoriented and optimized cleaning concepts. The latest research and approaches are enhancing jet efficiency and highlight their potentials for future process strategies.
\end{abstract}

Keywords Cleaning $\cdot$ Filter media $\cdot$ Filter cloth $\cdot$ Biophysics of adhesion $\cdot$ Wash jets $\cdot$ The beverage industry

\begin{tabular}{|c|c|}
\hline \multicolumn{2}{|c|}{ Abbreviations } \\
\hline CIP & Cleaning in place \\
\hline EHEDG & European Hygienic Equipment Design Group \\
\hline VDMA & Verband Deutscher \\
\hline \multirow[b]{2}{*}{ (X)DLVO } & Maschinen- und Anlagenbau e.V. \\
\hline & (X) Derjaguin, Landau, Verwey, Overbeek \\
\hline D-D & Disk-disk \\
\hline \multirow{2}{*}{$\begin{array}{l}\text { S-D } \\
\text { S-S }\end{array}$} & Sphere-disk \\
\hline & Sphere-sphere \\
\hline \multicolumn{2}{|c|}{ Variables } \\
\hline$A \quad \mathrm{Ar}$ & Area $\left[\mathrm{m}^{2}\right]$ \\
\hline $\mathrm{Pa}$ & Particle distance $[\mathrm{m}]$ \\
\hline Po & Polarizability, $\mathrm{A}^{2} \mathrm{~s}^{4} \mathrm{~kg}^{-1}$ \\
\hline Di & Diameter $[\mathrm{m}]$ \\
\hline $\mathrm{Bo}$ & Boundary layer thickness [m] \\
\hline
\end{tabular}

Dominik Ulrich Geier

dominik.geier@tum.de

1 Chair of Brewing and Beverage Technology, Technical University of Munich, Weihenstephaner Steig 20, 85354 Freising, Germany
E $\quad$ Energy $[\mathrm{J}]$

$\varepsilon \quad$ Relative permittivity, $\mathrm{AsV}^{-1} \mathrm{~m}^{-1}$

$\varepsilon_{0} \quad$ Electric field constant, $\mathrm{AsV}^{-1} \mathrm{~m}^{-1}$

$\epsilon_{\text {Fluid }}$ Backflow effect [-]

$F \quad$ Force [N]

$f \quad$ Frequency [Hz]

$G \quad$ Gibbs free/adhesion energy [J]

$g \quad$ Earth acceleration $\left[\mathrm{m} \mathrm{s}^{-2}\right]$

$H \quad$ Hamaker constant [J]

$h \quad$ Planck's constant [J s]

万 Lifshitz constant, J

$k_{\mathrm{B}} \quad$ Boltzmann constant [ $\mathrm{J} \mathrm{K}^{-1}$ ]

$\kappa \quad$ Debye-Hückel parameter $\left[\mathrm{m}^{-1}\right]$

$l \quad$ Length [m]

$l_{0} \quad$ Equilibrium distance $[\mathrm{m}]$

$\lambda \quad$ Decay rate of polar interactions [m]

$M \quad$ Mass [kg]

$\dot{m} \quad$ Mass flow $\left[\mathrm{kg} \mathrm{s}^{-1}\right]$

Oh von-Ohnesorge number [-]

$\mu \quad$ Dipole [C m]

$\eta \quad$ Dynamic viscosity [Pa s] 
$p \quad$ Pressure $[\mathrm{Pa}]$

$R_{\mathrm{a}} \quad$ Mean roughness $[\mu \mathrm{m}]$

Re Reynolds number [-]

$R_{\mathrm{q}} \quad$ Square roughness [ $\left.\mu \mathrm{m}\right]$

$\Phi \quad$ Porosity [-]

$\rho \quad$ Density $\left[\mathrm{kg} \mathrm{m}^{3}\right]$

$T$ Temperature [K]

$t \quad$ Time [s]

$\tau \quad$ Wall shear stress $\left[\mathrm{kg} \mathrm{m}^{-1} \mathrm{~s}^{-2}\right]$

$\Delta U \quad$ Interaction energy [J]

$v \quad$ Velocity $[\mathrm{m} / \mathrm{s}]$

$\vartheta \quad$ Kinematic viscosity $\left[\mathrm{m}^{2} \mathrm{~s}^{-1}\right]$

$x \quad x$ coordinate $[\mathrm{m}]$

$\zeta \quad$ Zeta potential [V]

\section{Introduction}

Filtration is a central unit operation in modern beverage production. In many relevant applications, filter media are the centerpiece of filtration systems. Filter systems comprise a filter medium featuring the barrier function and an apparatus keeping the filter medium in the desired position and providing mechanical functionality [130]. Filter media, e.g., woven filter cloths or membranes, regulate filtration processes via pore sizes, adhesive material properties, or other specific characteristics [145]. In the beverage industry, filter media assist in creating interstage products or the actual final products for consumption. They avoid unwanted turbidities or deposits that usually do not fit into the general consumer perception of healthy merchandise. Besides, the filtration of beverages results in longer storage life and increases beverage stability due to the removal of microorganisms and suspended solids [25].

Textile filter cloths are present in numerous forms and have applications in beverage production. Due to increasing consumer interest, product safety, and new legal requirements, the filtration industry highlights research and development of filter cloths. Since decades, polypropylene, polyethylene, polyester, or polyamide polymer filter cloths are state of the art [32, 66, 103]. Such filters increase filtration performance and system durability. However, after filtration, cohesive filter cakes require a full discharge to guarantee efficient filtration of subsequent batches. Unfortunately, this discharge is mostly incomplete, and the remaining residues need a separate removal [92, 166]. Production conditions (e.g., temperature, cake size) favor residue adhesion on the filter surface, which results in filter blinding and fouling [47]. A closer look at filter cloth cleaning reveals a big dilemma: During the filtration process, the growth of a filter cake on the filter surface is necessary to generate sufficient filtration performance and product yield. However, this desired adhesion has a detrimental effect on the cleaning process. Residue removal is only successful if the adhering forces are overcome $[45,92,131]$. It can thus be concluded that filter cloths are designed for proper filtration performance and not for optimal cleanability [156]. Nevertheless, cleanability determined by the combination of the surface properties and the contamination type is essential in order to avoid production-related spoiling of beverages.

For decades, cleaning is one of the primary endeavors in food and pharmaceutical processing plants $[21,63,101,106$, 160]. This testimony of the literature incorporates the development of appropriate design features of the equipment. In mechanical engineering, the construction of easily cleanable surfaces and hygienic production equipment are standard features of hygienic design. The main goals are safe and efficient cleaning in production cycles and the avoidance of crosscontamination [114, 123, 124]. However, respective regulations or concepts for filter media are still unknown [106]. Due to involved, unpredictable beverage residues, organic and inorganic fouling decrease product safety, filtration performances, and cleaning efficiency [160]. Especially waterinsoluble particle contamination adheres to filter cloth due to adhesive forces. If located in the inner filter structure, they are difficult to remove using water or cleaning agents $[45,97$, 176]. These reasons postulate the use of reliable cleaning concepts. Requirements for a suitable cleanability have to be as high as the requirements for the process itself [167].

Consequently, it is necessary to extend efforts in cleaning research and development. In the beverage industry, water cleaning (rinsing or mixed with cleaning agents), which is common in cleaning tanks or pipe systems, removes residues efficiently by wash jets $[52,160]$. Indeed in the future, it is inevitable to highlight water jets for cleaning of filter cloth increasingly. Exemplary wash jet systems already carry out cleaning tasks in filter presses or belt filters. Parameters like nozzle geometry or operating pressure ensure adjustable and sufficient cleaning efficiency [101]. There is, however, still a significant deficiency in the concept design, processing knowledge, and ecological and economic optimization, which have to be surveyed by corresponding research efforts.

The focus of this review article is the cleaning of filter cloth with wash jets applied in the production of beverages. An overview of filter cloth and design features shows its potentials and limitations in cleaning processes. A review of the biophysical properties delivers insight into interactions between beverage contaminants and filter cloths and how they have to be exceeded by a wash jet. Finally, the application of wash jets for the cleaning of filter media is part of a discussion. The detailed jet analysis includes the fluid mechanical principles while leaving the nozzle, impacting on the filter surface and removing residues.

\section{Goals and Importance Regarding Cleanability}

Careless treatment and incorrect processing of beverages cause diseases or negatively influence health. During 
production, beverages can easily absorb contaminants, microorganisms, or other particles, which are unfit for consumption, unhealthy, or even toxic. In the production chain, industrial equipment needs cleaning concepts that agree to the highest possible hygienic standards $[78,122,147,178]$. The significance of cleaning processes also becomes apparent in the number of guidelines and configuration proposals for hygienic design in the food-producing industry. According to the literature $[45,47,177]$, the goals of sufficient cleanability are as follows:

- Removal of deposits (constant equipment performance)

- Clearance of beverage arrears (prevention of microorganism growth)

- Fulfillment of consumer requirements (healthy and safe products)

- Achievement of secure production cycles (avoidance of cross-contamination)

- Extension of equipment life and long-term maintenance of value

In separation processes, filter media are in direct contact with the product, which requires an increased awareness when designing cleaning concepts. Spoiled filter media need sufficient and exact adjusted cleaning concepts, which reliably remove residues and provide clean conditions for subsequent product cycles. The specific objectives of filter cleaning are as follows:

- Sufficient cake discharge

- Successful removal of residues and fouling

- Gentle treatment of filter media (extended lifetime)

- Using less concentrated chemicals (economic and ecologic advantages)

- Short cleaning time (avoidance of extended downtime)

Filtration processes in the beverage industry stabilize final products or convert pre-stages [13]. After filtration, many substances remain as residues on the filter cloth. Soil is categorizable according to physical, chemical, or microbiological criteria [173, 177]. Beverages consist of different ingredients like proteins, carbohydrates, or fats, which form a complex biological contamination matrix [151]. Furthermore, specific fundamental removal mechanisms complicate cleaning. Table 1 characterizes different residue types, their occurrence, and cleaning as an unpredictable bottleneck in modern beverage processing.

\section{Woven Filter Cloth—a Hard-to-Clean Surface}

Filter cloths consisting of plastic polymers (e.g., polypropylene and nylon) represent the most significant market share among filter fabrics, which underlines their economic relevance $[103,130]$. The main utilizations are solid-liquid separation processes like cake filtration and surface filtration, which are common in the beverage industry [5, 13]. Concerning beverages, exact and sparing filtration is inevitable to separate solids from liquids while keeping valuable or value-adding substances in the product. Filter cloths are insertable into different filter systems and thus guarantee flexibility and precise selectivity (see Table 2). Aperture sizes or pore sizes-resulting from thread thickness, weave, and construction - have to be product- and residue-specific. Due to these reasons, filter cloths create complex and hard-to-clean geometries with high surface roughness.

\section{Filter Cake Formation and Fouling on Filter Media}

Filter cakes (retentate) grow over time and are the most used mechanism for filtration [66]. In general, the classification of cake filtration is possible in two categories: cross-flow filtration describes a tangential product approach flow toward filter media by keeping filter cake thickness constant in a defined size $[28,167]$. In contrast, dead-end filtration is more static: retentate particles cluster on filter surface while filter cakes expand [39]. Large retentate fragments generate permeable cakes where fluids have many passing possibilities. However, smaller particles result in more dense, filter performance-reducing cakes. In the beverage industry, production operators often add filter aids (e.g., diatomaceous earth or perlite) if the product to be filtered is not capable of satisfactory separating processes [13].

During beverage filtration, the fouling of filter media always occurs due to retentate or product contamination [86]. Process performances (flux) will decrease with time, and grave pore blinding is caused [17, 96, 167]. Although this problem is more severe in membranes, it also plays an essential role in filter cloths due to production limitations. Consequently, after almost every filtration process, sufficient cake discharges have to take place to ensure proper filtration performances in subsequent product cycles and process cost reduction [66]. Cake discharge occurs by gravity (e.g., filter press) or mechanically using cutting or vibration-based equipment [173]. However, large amounts of residues remain on filter cloths due to the moisture of solid-liquid operations [66]. In this context, water jets are the ideal cleaning option for combining mechanical cleaning effects with chemical additives.

\section{Filter Materials}

Besides the filterability, cloth material also determines the cleanability [130]. Leipert and Nirschl [92] showed that polymer filter cloth showed no differences in cleanability. Since polymers basically have similar material features and thus 


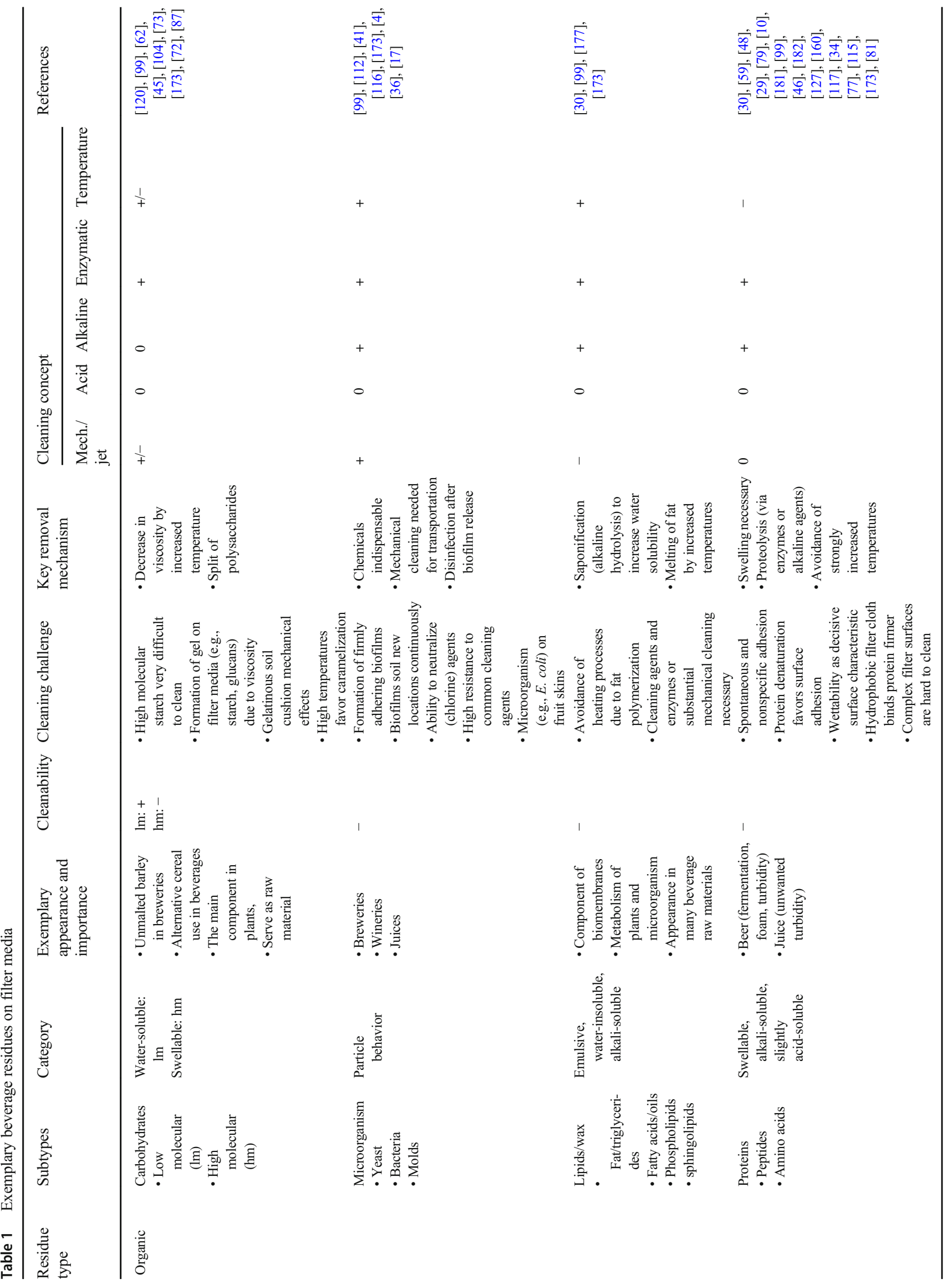




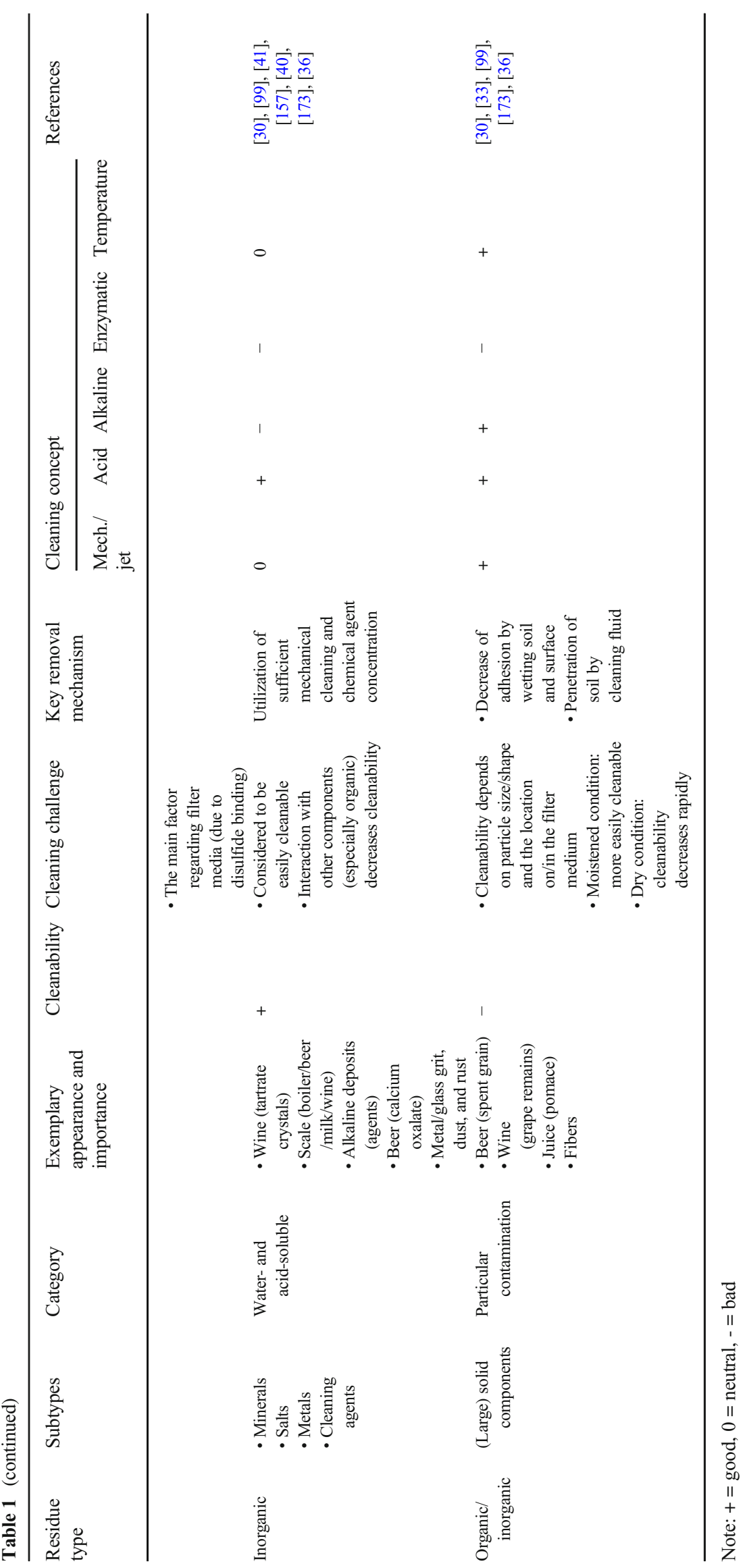


Table 2 Applications of filter cloths in the beverage industry

\begin{tabular}{|c|c|c|c|}
\hline Application & Filter system & Task & Reference \\
\hline Water treatment & Drum filter, (vacuum) belt filter & Separation of solids & [82] \\
\hline \multirow[t]{2}{*}{ Wine } & \multirow[t]{2}{*}{ Filter press } & Decrease of must turbidity & [40] \\
\hline & & Clarification of polyphenols and polysaccharides & [86] \\
\hline Beer (pre-stage mash) & Filter press, rotating disk filter & Separate beer wort from spent grain & [112] \\
\hline Syrups and brines & Filter press & Removal of unwanted particles; sugarcane juice production & {$[13],[86]$} \\
\hline \multirow[t]{3}{*}{ Fruit and vegetable juices } & \multirow{3}{*}{$\begin{array}{l}\text { Belt filter, filter press, filter } \\
\text { centrifuge }\end{array}$} & Detachment of suspended and colloidal particles & [167], [68] \\
\hline & & Removal of polyvinylpolypyrrolidone- or bentonite-treated product & {$[151],[184]$} \\
\hline & & Separation in pulp and (microorganism-free) clarified juice & [28] \\
\hline $\begin{array}{l}\text { Product recuperation via } \\
\text { yeast separation (beer, wine) }\end{array}$ & Filter centrifuge, filter press & Removal of yeast cells (defined size) & [7] \\
\hline
\end{tabular}

interface properties, the cleaning dependency between different materials is negligible. However, the cloth material requires careful considerations regarding chemical and physical resistivity and sensitivity. In separation processes, different pressures, temperature levels, or other special conditions occur. Although they are not as extreme as in the chemical industry, filter materials have to resist environmental conditions well enough to guarantee acceptable lifetimes [5]. This fact is also crucial for the cleaning and regeneration of filter cloth by using increased process parameters and high-concentrated cleaning agents. By the current state of scientific knowledge, the application range of cleaning is limited in the beverage industry. Because of high hygiene standards and microbiological safety, the use of chemical cleaning agents is, in most cases, inevitable [160]. Nevertheless, the various kinds of polymeric filter cloth are sensitive at certain processing or cleaning conditions due to specific material properties. Also, national or international laws, e.g., FDA regulations, have to be considered when choosing the material. Polymer fabrics require sufficient declaration of conformity as indirect food additives, and also corresponding threads have to agree with equivalent legislation [5]. An additional coating of yarns or complete filter fabrics also has to comply with legal requirements as well [130]. Table 3 gives an overview of the properties of different filter media materials (filter cloth in particular and also membranes). The average values of the specific material properties given in Table 3 originate from the scientific literature and the online database CAMPUS (Computer-Aided Material Preselection by Uniform Standards).

In most cases, these values depend on the manufacturer (here with the example of the RIWETA 4.2 online database), which can lead to individual deviations in the properties of commercially available polymers. The selection and the applicability of the material depend on the process, product, performance, and desired cleaning behavior. Regarding cleaning, the most certain characteristics are mechanical and chemical factors due to their strong influence on the filter lifetime.
Additionally, a high dependency between material and cleanability regarding surface properties like free surface energy is expected [20, 21, 71, 101, 102].

In the beverage industry, most common chemical cleaning agents are strongly alkaline or acidic, which are potentially abrasive to synthetic yarns $[160,167]$. Novel agents, including oxidizers or enzymes, increase cleaning and disinfection efficiency. However, they are difficult to handle (enzymes) or considered to be the most dangerous agent type (oxidants). Generally, chemicals have to be used in exact concentrations to guarantee sufficient cleaning and to ensure that no contamination remains. Considering the problematic cleanability of filter cloths, incorrectly concentrated agents reduce the stability and lifetime of a filter due to abrasive effects and resulting yarn impairment. These unwanted aspects result in more frequent cloth changes, more extended system downtime, and higher process costs. Regarding physical stress, abrasion is caused by temperature gradients, filtration pressures, mechanical cleaning, or the product to be filtered. If there are particles with sharp edges, the filter cloths have to be designed robustly and stiffly [66].

The challenge of choosing the right material becomes apparent regarding the two most common filter polymers (see Table 3). According to Horrocks and Anand [66], polypropylene is the most widely used thread material in solid-liquid separations due to its high acidic and alkaline resistance. However, this polymer is susceptible to oxidizing agents and has low physical resistance to mechanical stress (e.g., high temperatures). In contrast, polyamide offers high abrasion resistance but has weaker chemical resistance. In conclusion, there is a considerable need for better adjustable cleaning mechanisms, e.g., via wash jets, to extend the lifetime of filter cloths.

\section{Mesh Types}

Since humans started to weave yarns into textiles, a variety of different weaves found their way into everyday life. Many of 
Table 3 Overview of different materials used for filter media

\begin{tabular}{|c|c|c|c|c|c|c|c|c|c|}
\hline \multirow[t]{2}{*}{ Material } & \multirow[t]{2}{*}{ Abbreviation } & \multicolumn{3}{|c|}{$\begin{array}{l}\text { Chemical cleaning } \\
\text { agent resistance }\end{array}$} & \multirow{2}{*}{$\begin{array}{l}\text { Maximal } \\
\text { working } \\
\text { temperature } \\
{\left[{ }^{\circ} \mathrm{C}\right]}\end{array}$} & \multirow{2}{*}{$\begin{array}{l}\text { (Physical) } \\
\text { abrasion } \\
\text { resistance }\end{array}$} & \multirow{2}{*}{$\begin{array}{l}\text { Absorbency } \\
\text { for water (\% } \\
\text { wt) }\end{array}$} & \multirow[t]{2}{*}{ Additional remarks } & \multirow{2}{*}{$\begin{array}{l}\text { References } \\
\text { Generally referenced } \\
\text { by the CAMPUS } \\
\text { online database [27] } \\
\text { and with additional } \\
\text { references below }\end{array}$} \\
\hline & & Acid & Alkali & Oxidant & & & & & \\
\hline $\begin{array}{l}\text { Polyvinylidene } \\
\text { fluoride }\end{array}$ & PVDF & +++ & +++ & + & $120-160$ & +++ & $0.1-1.0$ & $\begin{array}{l}\text { High } \\
\text { hydrophobicity } \\
\text { inhibits filtration }\end{array}$ & $\begin{array}{l}\text { [130]; [135]; [180]; } \\
\text { [91]; [81] }\end{array}$ \\
\hline Polyethersulfone & PES & ++ & ++ & - & 190 & ++ & $0.7-2.1$ & Prone to fouling & $\begin{array}{l}{[134],[55],[185]} \\
\quad[139-143]\end{array}$ \\
\hline Polyamide 6.6 & PA6.6 & - & ++ & - & $105-120$ & +++ & $6.5-8.3$ & $\begin{array}{l}\text { Common material } \\
\text { for filter cloth }\end{array}$ & [130], [14], [66] \\
\hline Polyamide 12 & PA12 & - & ++ & - & $105-120$ & +++ & $6.5-8.3$ & $\begin{array}{l}\text { High physical } \\
\text { resistance }\end{array}$ & {$[130],[66]$} \\
\hline Polypropylene & PP & +++ & +++ & - & 120 & + & $0.01-0.1$ & $\begin{array}{l}\text { Common material } \\
\text { for filter cloth }\end{array}$ & {$[130],[66]$} \\
\hline Polyamide 6 & PA6 & - & 0 & - & $105-120$ & +++ & $6.5-8.3$ & $\begin{array}{l}\text { Low resistance to } \\
\text { chemical } \\
\text { cleaning agents }\end{array}$ & [130], [139-143] \\
\hline $\begin{array}{l}\text { Polyethylene } \\
\text { terephthalate }\end{array}$ & PET & + & - & 0 & 100 & ++ & $0.2-0.5$ & $\begin{array}{l}\text { Poor to chemical } \\
\text { cleaning agents; } \\
\text { stable to } \\
\text { beverage } \\
\text { ingredients }\end{array}$ & [14], [139-143] \\
\hline $\begin{array}{l}\text { Polyethylene } \\
\text { - High density (hd) } \\
\text { - Low density (ld) }\end{array}$ & $\mathrm{PE}$ & +++ & +++ & - & $\begin{array}{c}65-74(\mathrm{ld}) \\
93-110 \\
\text { (hd) }\end{array}$ & 0 & 0.01 & $\begin{array}{l}\text { Most utilized } \\
\text { polymer material }\end{array}$ & {$[130],[66]$} \\
\hline $\begin{array}{l}\text { Polybutylene } \\
\text { terephthalate }\end{array}$ & PBT & + & 0 & 0 & 100 & ++ & $0.25-0.5$ & $\begin{array}{l}\text { Similar properties } \\
\text { as PET }\end{array}$ & [66], [139-143] \\
\hline Polyether ether ketone & PEEK & + & + & 0 & 220 & ++ & $0.3-0.5$ & $\begin{array}{l}\text { High-temperature } \\
\text { tolerance }\end{array}$ & {$[66],[6]$} \\
\hline Polyamide 11 & PA11 & - & ++ & - & 100 & +++ & $6.5-8.3$ & $\begin{array}{l}\text { High physical } \\
\text { resistance }\end{array}$ & {$[66]$} \\
\hline Polytetrafluoroethylene & PTFE & +++ & +++ & ++ & 240 & 0 & $<0.1$ & $\begin{array}{l}\text { High resistance to } \\
\text { soiling and } \\
\text { cleaning agents; } \\
\text { poor physical } \\
\text { resistance }\end{array}$ & [66], [6], [139-143] \\
\hline $\begin{array}{l}\text { Polyvinylidene } \\
\text { chloride }\end{array}$ & PVDC & +++ & ++ & ++ & 75 & + & $\mathrm{n} / \mathrm{a}$ & $\begin{array}{l}\text { Agrees with FDA } \\
\text { in packaging } \\
\text { materials; less } \\
\text { commonly used } \\
\text { for beverage } \\
\text { filtration }\end{array}$ & {$[66]$} \\
\hline Polyphenylene sulfide & PPS & ++ & +++ & 0 & 190 & + & 0.5 & $\begin{array}{l}\text { Less beverage } \\
\text { relevance; brittle }\end{array}$ & {$[66],[180],[6]$} \\
\hline Polyvinyl chloride & PVC & +++ & +++ & 0 & 75 & ++ & Little & $\begin{array}{l}\text { Less relevant for } \\
\text { beverages due to } \\
\text { plasticizers }\end{array}$ & {$[66]$} \\
\hline Cotton & - & - & + & 0 & $90-93$ & $\mathrm{n} / \mathrm{a}$ & $16-22$ & $\begin{array}{l}\text { Historic filter } \\
\text { material; no } \\
\text { relevant use } \\
\text { today }\end{array}$ & {$[130],[66]$} \\
\hline
\end{tabular}

Note: $+++=$ very good,$++=$ good,$+=$ adequate, $0=$ average,$-=$ bad

these developed web types are also suitable for filter fabrics $[66,103]$. In the production of textile filters, different threads are interweaved and form distinctive filter structures. Each filter cloth is unique due to different thread diameters, 
Table 4 Influence of the yarn type on the cleanability behavior of the filter fabric

\begin{tabular}{lccccc}
\hline Type & $\begin{array}{l}\text { Lowest cake moisture } \\
\text { after filtration }\end{array}$ & $\begin{array}{l}\text { Cake } \\
\text { discharge }\end{array}$ & $\begin{array}{l}\text { (Physical) abrasion } \\
\text { resistance }\end{array}$ & $\begin{array}{l}\text { Cleanability (via } \\
\text { wash jets) }\end{array}$ & References \\
\hline Monofil & +++ & +++ & + & +++ & [66], [6] \\
Multifil & ++ & ++ & ++ & ++ & + \\
Staple & + & + & +++ & + & \\
\hline
\end{tabular}

Note: $+++=$ very good,$++=$ good,$+=$ adequate materials, and mesh types that worsen the cleaning predictability [99, 130].

In the beverage industry, woven filters mainly consist of single monofil (one single thread) or multifil threads (composed of several threads) in single or multilayer filters. The advantages of multifil threads are enhanced safety and improved lifetime by hindering thread breakage [130]. In terms of cleanability, the thread choice is vital due to the moistening behavior of filter cakes or abrasion resistance. Table 4 illustrates the influence of the thread on the cleanability of a whole mesh.

Filter cloths are used singly in combination with a second cloth layer or interlinked with porous membranes. Combinations of several filter cloths are defined as composite fabrics and are used to adjust a different filterability [130]. This publication does not consider needle felts or fleeces due to their subordinated role in beverage production.

The smallest particle size to be filtered determines the choice of the mesh, the pore size of which depends on the construction and thread thickness $[5,6,66]$. The weave type forms distinct geometric structures by particular arrangements of chaining and weft threads. While chaining threads extend in the web direction, weft threads are perpendicular to this direction and enlace the longitudinal warp threads [138]. General filter cloth properties (e.g., thread diameter, porosity, or pore velocity) are central to determine the cleaning efficiency of different filters [173]. Especially porosity seems to be a possible factor in comparing the cleanability of various filters. With this parameter, it is possible to determine the flow rates of cleaning jets on or in filter media. According to the literature $[136,173]$, the filter porosity $\Phi$ is calculated according to Eq. 1.

$\Phi=\frac{v_{\text {total }}-v_{\text {yarn }}}{v_{\text {total }}}$

$V_{\text {total }}$ is the whole volume of the mesh, while $V_{\text {yarn }}$ represents the volume of weft and chaining threads. Commonly used weave types in industrial textiles are plain, twill, and satin weaves (see Fig. 1) [130]. There are many areas, stream shadows, and dead spots that are decreasing cleanability. Accurately fitting particles located in these hard-to-clean areas are difficult to remove [97].

According to Purchas and Sutherland [130], the twill weave mainly has more significant gaps in the meshes, which results from the inhomogeneously woven threads. This construction enhances the float in separation processes and creates deeper layers, which are easier to reach for wash jets. The utilization of satin weaved cloths even enhances the floating effect. Here, structures are increasingly irregular, which results in very smooth surfaces. This filter evenness reduces the likelihood of firmly adhering particles in deeper meshes and care for better cake discharges with fewer residues [66]. Thus, on the one hand, minor residue disposition is favoring cleaning processes. On the other hand, hard-to-clean zones are more comfortable to reach using wash jets, improving effectivity. Table 5 illustrates the common weave types of industrial textiles.

After weaving, almost every cloth undergoes an after-treatment. This conditioning is necessary for stability, surface enhancement, and permeability modification of the filter fabric [57]. Such treatments improve the filtration process but also increase the cleanability of filter media. Calendering of filter cloth enhances the cake discharge and thus favors cleaning [5]. Additionally, calendering can regulate permeability, which supports backwashing methods [66]. For calendering, the filter cloth runs through heated mills that smooth the surface [6]. Supernatant parts of yarns can hinder sufficient cake discharge and can thus influence cleaning efficiency. Singeing removes protruding parts by contact with gas flames or hot metal boards [66].

\section{The Roughness of Filter Cloths}

Following the literature [26, 74], surface roughness has significant adhesion influence on biological residues located on surfaces. Due to their complex structures, the transformation of hygienic design concepts to filter media is difficult, which requires reliable cleaning methods. The topography of filters strongly affects the adhesion of biomolecules [42, 111]. Therefore, surface geometry and adhering contamination are central to the strength of adhesive forces [76, 122, 175]. Binding points of adhering particles depend on the roughness profile. Particles located between two threads cause more than one contact point with the filter. Regarding filter cloths, we must differentiate between thread roughness and whole meshes. For textile filters, it is possible to describe the aperture with the same roughness analysis tools as standard surfaces. Here, the values of the mean roughness $R_{a}$ and the square roughness $R_{\mathrm{q}}$ are decisive. Moeller [106] developed more 
Fig. 1 Commonly used weaved types of filter cloths: a plain weave, b twill weave, c Satin weave a

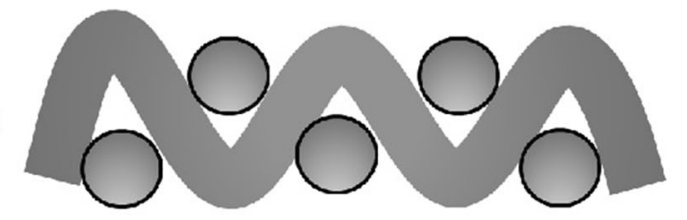

b

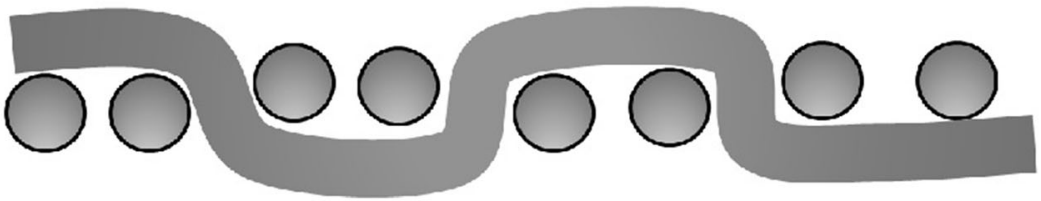

C

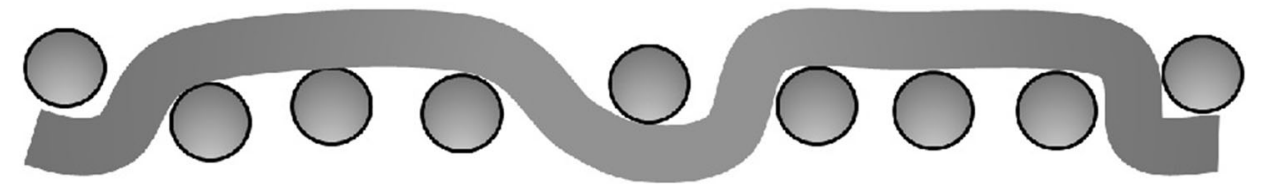

precise methods to characterize the filter cloth roughness. Particle residues that fit in the roughness profile are difficult to remove due to several contact points (see Fig. 2).

\section{Biophysics of Particle Detachment}

Particles or other colloids adhere to surfaces due to interatomic or intermolecular adhesive forces [101]. According to Weigl [175], these types of forces are essential in many processes like agglomeration, crushing, or transportation of solids. Regarding cleaning operations, these interactions and similar effects are the critical aspects in removing contamination from surfaces, e.g., cleaning filter cloths by water flows. Such wash jets $\left(F_{\text {jet }}\right)$ have to overcome any binding mechanisms $\left(F_{\text {Adhesion }}\right)$ and release contamination from filter cloths $[92,122,175]$.

$F_{\text {Jet }}>F_{\text {Adhesion }}$

The definition of $F_{\text {Jet }}$ is given in the "Fluid Mechanical Principle of Wash Jets" section and of $F_{\text {Adhesion }}$ in the "Adhesive Forces" section. As already mentioned above, successful removal requires detachment work. Regarding the

Table 5 Exemplary types of gauze construction for filter cloths

\begin{tabular}{lccc}
\hline Type name & Abbreviation & Cake discharge & References \\
\hline Plain (reverse Dutch) & PRD & + & [173], [66], [6] \\
Twill & TWL & ++ & \\
Satin & STN & +++ & \\
\hline
\end{tabular}

Note: $+++=$ very good,$++=$ good,$+=$ adequate common physical approach in Eq. 3, the adhesive forces are linkable to the detachment work $W$.

$W=\int_{0}^{a} F(x) \mathrm{d} x$

The range [0:a] distinguishes the particles on the surface (= 0 ) and the particles at a certain distance from the surface $(=a)$. The acting work leads to a change in energy balance. Thus, the energy of the detachment has to outstrip the adhesion energy. While the detachment energies include the jet properties (e.g., kinetic energy), the interaction energy consists mostly of the adhesion and repulsion. Several models (e.g., DLVO or XDLVO) determine the interdependency of these effects.

Furthermore, the particle has to be moved to a particular distance $a_{x}$ so that adhesive forces do not affect anymore (see also Fig. 3). Regarding the impact forces of a water jet, the impact area is a decisive aspect. Here, the acting hydrodynamic jet force and the impact surface must cohere with effecting pressure distributions on the filter surface. The resulting pressures are responsible for the area-specific cleaning effect and generate the necessary mechanical impulses on the contamination as well as the wall shear stress (see "Impinging JetForces on the Residues on the Filter Cloth" section). Palabiyik et al. [125] also concluded rheology as necessary for a proper cleaning design. With a certain particle distance, the prevention of force recovery and complete deportation of unwanted residues by using liquid films after the impact are desirable to guarantee sufficient cleaning efficiency [47, 183]. Different publications researched the cleaning kinetics of jets $[50,178]$.

Nevertheless, the type of application and soil are decisive as cleaning optimization often fails due to unknown adhesion mechanisms or detachment kinetics. To ensure sufficient cleaning, many companies in the beverage industry use exaggerated cleaning concepts. The following section gives an 
Fig. 2 Exemplary roughness profile of a filter cloth with exemplary particles of different sizes; mean roughness $R_{\mathrm{a}}=18.8$ $\mu \mathrm{m}$, square roughness $R_{\mathrm{q}}=22.4$ $\mu \mathrm{m}$; measurement of the roughness occurred via a confocal laser scanning microscope; the illustration is the authors' own creation

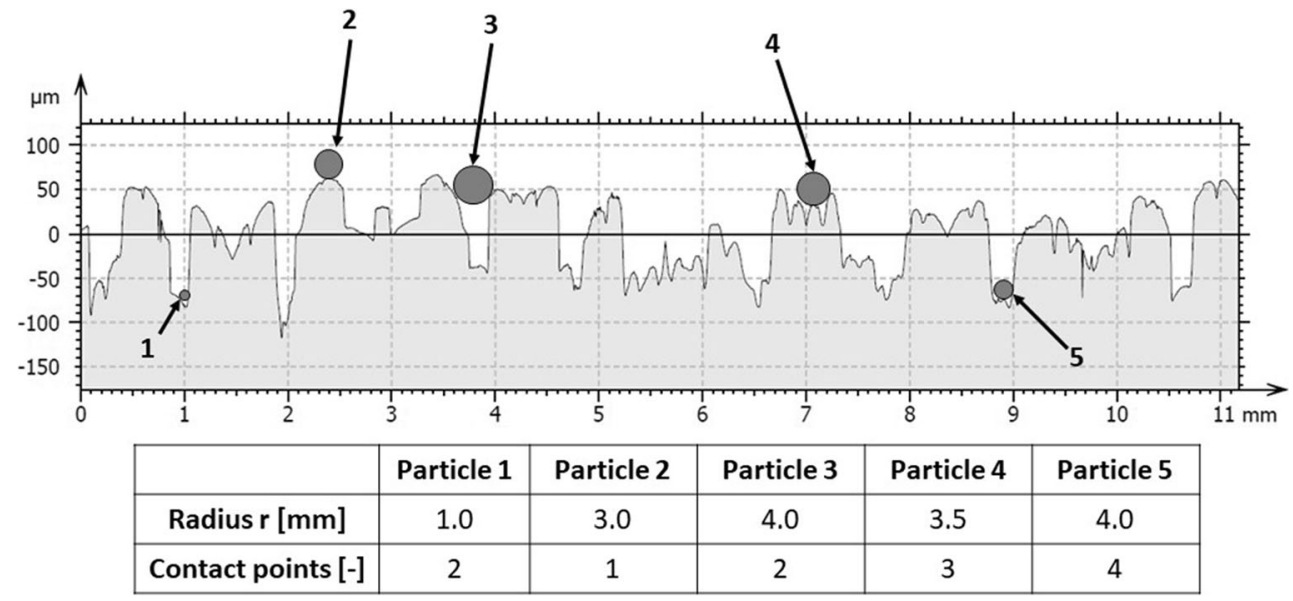

overview of acting adhesive forces, how they work, and how several models can determine their interaction.

\section{Adhesive Forces}

Purchas and Sutherland [130] have stated that adhesion is a central filtration characteristic depending on the application field. Its mechanism belongs to attractive intermolecular forces like van der Waals or electrostatic forces $[69,101]$. Once such forces arise, they are the critical aspect of cleaning. Concerning cleaning with nozzle, impinging jets have to affect the filter surface with a minimum of energy to release existing attractive forces [122]. Besides adhesion, cohesion - binding forces between the residue particles - is also central to obtaining appropriate cleaning degrees [47, $106,175]$.

Three range-dependent groups classify adhesive forces. The first group includes long-range forces, which act in the contact zone and beyond due to greater strength and more extended ranges. Exemplary forces are van der Waals forces and electrostatic forces. Short-range forces belong to the second group and define chemical bond forces and hydrogen bonds (e.g., Lewis acid-base interactions). The third group contains forces, which arise by reactions of the boundary layer, e.g., colloids interacting with the surface [40, 84]. Here, particles possess nonspecific and specific adhesive attitudes
Fig. 3 Interactions between a suspended particle and the surface (overlap of adhesive van der Waal attraction and repellent electrostatic potential) illustration is an the authors' own creation and was adapted from Adair et al. [1] and Koglin [80]

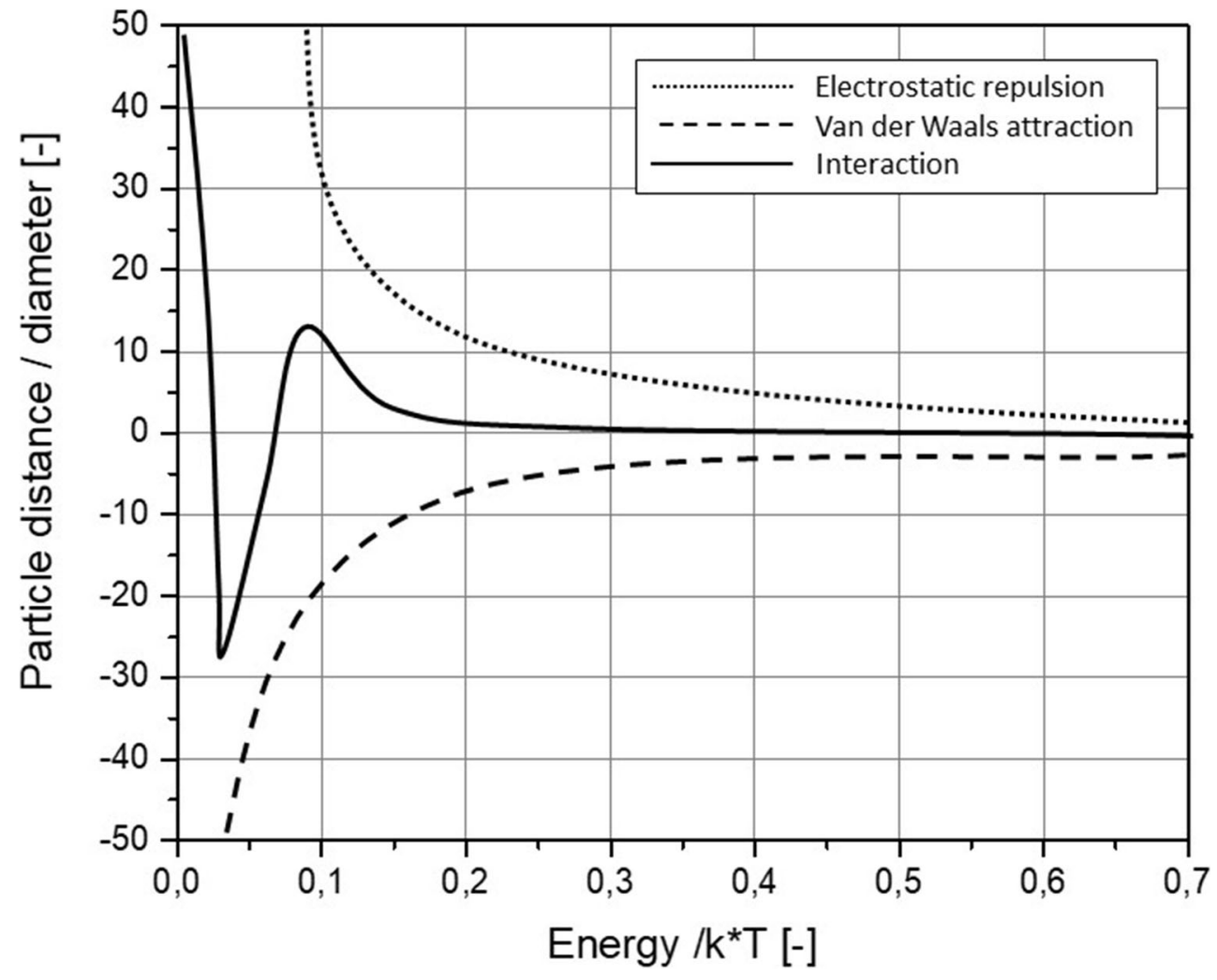


toward the filter structure. Nonspecific adhesive forces arise from a combination of physiochemical influences.

In contrast, the specific interaction between particles, e.g., microorganisms, and filter surfaces depend on stereochemical interactions between corresponding substances on the surface, e.g., adhesion [108]. Besides the named adhesive influences, there are other influences like capillary forces, capillary condensation, solid bridges, and form closure [106, 148]. However, they are negligible in fluid systems [158], such as the solid-fluid filtration of beverages. The following subchapters illustrate the three most relevant adhesive forces.

\section{Lifshitz-van der Waals Interactions}

Central components of particle adhesion are Lifshitz-van der Waals interactions, which are boundary layer forces. The categorization of these interactions is in Keesom (interactions of permanent dipoles), Debeye (magnetic induction interactions of permanent dipoles), and London forces (dispersion forces without permanent dipoles) $[69,85]$. Although these forces arise inside solids, they are mainly acting outside of them. They make solids cling to a surface or other particles due to dipole interactions [98, 108]. Atoms consist of an atomic nucleus surrounded by electrons in the nuclear shell. According to Heisenberg's uncertainty principle, which states that there is no specific location of the electrons around the atomic nucleus, atoms are fluctuant dipoles [60, 69]. This fluctuating charge distribution is responsible for the Lifshitz-van der Waals forces due to dipole charge-related attraction. The adhesive strength depends on the material, particle diameter, and surrounding medium [175]. Moriarty et al. [108] define Lifshitz-van der Waals forces as the apolar energy component of adhesion.

According to the literature [171, 172, 175], there are different approaches to determine this force. The microscopic theory by Hamaker [56] describes interactions between single atoms and molecules, which are additive and not influencing mutually. Differentiation between different compound geometries due to various adhesion forms of contamination on filters helps to understand the adhesion determination. Here, the models of a disk to another disk (D-D), a sphere to a disk (S-D), or a sphere to another sphere (S-S) are commonly used to describe adhesive forces. Considering the Lifshitz-van der Waal interactions $F_{\text {Hamaker }}$, three different models (Eqs. 4-6) are deployed [56, 85, 131].

- Disk-disk model (D-D):

$F_{\mathrm{D}-\mathrm{D}}^{\text {Hamaker }}(a)=\frac{H}{12 \pi \times a^{3}}$

- Sphere-disk model (S-D):

$F_{\mathrm{S}-\mathrm{D}}^{\text {Hamaker }}(a)=\frac{H \times d}{12 \times a^{2}}$
- $\quad$ Sphere-sphere model (S-S):

$F_{\mathrm{S}-\mathrm{S}}^{\text {Hamaker }}(a)=\frac{H \times d_{1} \times d_{2}}{12 a^{2} \times\left(d_{1}+d_{2}\right)}$

The variable $H$ represents the Hamaker constant, while $d_{n}$ is the sphere diameter and $a$ the particle distance. Regarding particular contamination on the filter surface, the S-D and the $\mathrm{S}-\mathrm{S}$ models are most relevant. The second proposed theorythe macroscopic theory by Lifshitz - does not include the atomic structure. Furthermore, measurable properties like the dielectric constant are incorporated. The polarization of atoms is additionally influenced by neighboring atoms, which is neglected by Hamaker's microscopic theory [24]. Lifshitz includes such effects in his approach, which is measurable with Eq. 7 (S-D model) [94].

$$
F_{L i f s h i t z}=\frac{\hbar \bar{w} \cdot d}{16 \pi a^{2}}
$$

Here, the factor $\hbar \varpi$ represents the Lifshitz constant, $d$ is the diameter of the spherical particle, and $a$ the particle distance. The two theories are combinable via Eq. 8 [84, 171].

$$
\hbar \widetilde{w}=\frac{4}{3} \pi \mathrm{H}
$$

Other geometries are determinable by knowing this correlation. According to Rumpf [144], considering smooth spheres with sizes below $100 \mu \mathrm{m}$, the electrostatic or hydrogen bonds are negligible in contrast to Lifshitz-van der Waals forces. The surface roughness influences the strength significantly and decreases the Lifshitz-van der Waal interactions at specific roughness radii. Filter cloths possess a more complex and rough surface, which reduces the meaningfulness of the two theories above. However, they are the basis of further and more precise models, which include defined surface roughness [132, 133].

\section{Electrostatic Force-Attraction and Repulsion}

Electrostatic forces (EL), which arise between two charged surfaces, are essential regarding the adhesion or repulsion of contaminants [106, 108, 175]. Most liquid-solved particles have a charge, which results in an electric double layer due to the dissociation of functional groups [98]. Depending on the $\mathrm{pH}$ of the surrounding fluid, particles are positively or negatively charged [113, 175]. Consequently, the charge decides whether particles cling to a surface or repel. Around the particle, there is an accumulation of oppositely charged ions forming a diffuse layer, which makes the particle appear to be 
neutral [58]. For small distances between particle and surface, electrostatic forces of electrical conductors are determinable using Eqs. 9-11 [98, 175].

- Disk-disk model (D-D):

$F_{\mathrm{D}-\mathrm{D}}^{\mathrm{EL}}(a)=-\frac{1}{2 \pi} \times \varepsilon \times \varepsilon_{0} \times \zeta_{1} \times \zeta_{2} \times \ln \left(1+e^{-\kappa a}\right)$

- $\quad$ Sphere-disk model (S-D):

$F_{\mathrm{S}-\mathrm{D}}^{\mathrm{EL}}(a)=-\varepsilon \times \varepsilon_{0} \times \kappa \times \frac{1}{2} \times d \times \zeta_{1} \times \zeta_{2} \times \ln \left(1+e^{-\kappa a}\right)$

- Sphere-sphere model (S-S):

$F_{\mathrm{S}-\mathrm{S}}^{\mathrm{EL}}=-\varepsilon \times \varepsilon_{0} \times \kappa \times \frac{\frac{1}{2}\left(d_{1} \times d_{2}\right)}{d_{1}+d_{2}} \times \zeta_{1} \times \zeta_{2} \times \ln \left(1+e^{-\kappa a}\right)$

The variable $\varepsilon_{0}$ designates the electric field constant, $\varepsilon$ the relative permittivity of the medium between the adhering components, $\zeta_{i}$ the equivalent zeta potential of sphere/disk $i, \kappa$ the Debye-Hückel parameter, $d$ the diameter of the spherical particle, and $a$ the adhesion distance. In nature, the majority of particles and surfaces have a negative charge. Therefore, most electrostatic interactions are repulsive [108]. Formerly considerations yielded electrostatic forces as less critical than Lifshitz-van der Waals forces. For decades, scientific approaches regard electrostatic forces as central in describing and understanding particle adhesion due to natural surface roughness [144].

\section{Lewis Acid-Base Interactions}

Lewis acid-base forces $(L A B)$ describe attractive interactions of hydrophobicity and repulsion via hydration around surfaces [108]. These interactions are dominated by hydrogen bonds, which are even up to two times stronger than Lifshitz-van der Waal forces [75]. Hydrogen bonds require donors, which are atoms bond to other atoms (e.g., oxygen, nitrogen), and acceptors, which are additional oxygen, nitrogen, or fluorine atoms [85]. Adhesion arises due to the interaction of a charged hydrogen acceptor and an electronegative receptor. In solid-fluid filtration processes, this effect is central because water is both a hydrogen donor and a hydrogen acceptor [168]. The result is strong hydrogen bonds and firmly adhering colloids on the surface. Equations 12-14 show the geometry-related definitions [85].

- Disk-disk model (D-D):

$$
F_{\mathrm{D}-\mathrm{D}}^{\mathrm{LAB}}(a)=-\frac{1}{\lambda} \times \Delta G^{\mathrm{LAB}} \times e^{\frac{l_{0-a}}{\lambda}}
$$

- $\quad$ Sphere-disk model $(S-D)$ :

$$
F_{\mathrm{S}-\mathrm{D}}^{\mathrm{LAB}}(a)=-\pi \times d \times \Delta G^{\mathrm{LAB}} \times e^{\frac{l_{0}-a}{\lambda}}
$$

- Sphere-sphere model $(S-S)$ :

$F_{\mathrm{S}-\mathrm{S}}^{\mathrm{LAB}}(a)=-\frac{\pi \times d_{1} \times d_{2}}{d_{1}+d_{2}} \times \Delta G^{\mathrm{LAB}} \times e^{\frac{l_{0}-a}{\lambda}}$

The variable $d$ defines the equivalent diameter, $\Delta G$ is the adhesion energy, $l_{0}$ depicts the equilibrium balance between the considered adhesion partners, $a$ is the adhesion distance, and $\lambda$ is the decay rate of polar interactions.

\section{Models of Residue Adhesion}

Several theories are commonly used for modeling and determining colloid adhesion [76]. However, following Moriarty et al. [108], their suitability has to be discussed critically because they are not entirely appropriate in most cases. The majority of the models require surfaces to be as smooth as possible without any measurable topography. Furthermore, the product to be filtered has to be isotropic and should be of consistent composition. Both requirements are here hard to achieve due to rough filter topographies and complex beverage compositions. Following van Oss [168], further interactions (e.g., Lewis acid-base) are acting in biological systems, which reduce the adhesion prediction via DLVO and thermodynamic theory. However, both approaches have been used for particles (e.g., macromolecules, microorganisms) for years and are still state of the art. In addition to the thermodynamic and the DLVO theory, the XDLVO theory that also includes additional interactions (see Table 6) shows an extended approach.

\section{Thermodynamic Theory}

This theory describes adhesion by changing the Gibbs free energy of particles. This shift happens when the particles start to adhere to the filter surface. Moriarty et al. [108] assume that the distance between filter and particle is zero. Consequently, it is the total change of free energy which defines total available energy in closed systems. More accurate determinations require the incorporation of Lewis acid-base interactions and Lifshitz-van der Waal forces. Furthermore, this approach assumes reversible adhesive properties. Following the literature $[108,109]$, adhesion energy is defined by Eq. 15 .

$\Delta G_{\text {Adhesion }}=\Delta G_{\text {Lifshitz-vdW }}+\Delta G_{\text {Lewis-acid-base }}$

Here, $\Delta G_{\text {Adhesion }}$ is the Gibbs free energy shift of adhesion, $\Delta G_{\text {Lifshitz-vdW }}$ is the Gibbs free energy change of acting 
Lifshitz-van der Waals interactions, and $\Delta G_{\text {Lewis-acid-base }}$ includes Lewis acid-base forces. Adhesion takes place when the result of Eq. 15 is negative due to a more stable condition by decreasing the free energy.

\section{DLVO Theory-the Combination of the Adhesive Forces}

The most famous approach of the interaction of Lifshitz-van der Waal and electrostatic forces is the DLVO theory (named after Derjaguin, Landau, Verwey, and Overbeek), which defines interactions between the two forces [35, 170]. Depending on the distance between particle and surface, these forces influence each other and describe either residue adhesion or repulsion.

Considering Fig. 3, van der Waal forces act over small distances, while electrostatic forces affect considerable distances. For reaching adhesion, it is crucial to overcome energy barriers. DLVO is defined by Eq. 16 [108].

$E_{\mathrm{DLVO}}=E_{\mathrm{Lifshitz-vdW}}+E_{\text {Electrostatic }}$

$E_{\mathrm{DLVO}}$ is the total energy of the adhesion, and $E_{\mathrm{Lifshitz-vdW}}$ and $E_{\text {Electrostatic }}$ are the proportionate Lifshitz-van der Waals forces and electrostatic interactions, respectively. The most accurate results are determinable when the electrostatic forces are dominant.

This theory is suitable for describing bacterial adhesion [9, 12, 23]. However, other critical potential influences (e.g., steric forces) are not included [181]. The neglect of direct surficial impacts to bind or repel electrons limits the applicability (especially with particles of biological origin) [85].

\section{XDLVO Theory}

In contrast to the DLVO theory, the extended DLVO theory model (XDLVO) incorporates the influence of polar forces $[168,169]$. Following the literature $[12,108,126,186]$, it is the most advanced theory because it combines aspects of thermodynamic and DLVO theory resulting in a more accurate adhesion prediction. There are numerous publications, which favor this theory, especially for microorganism adhesion [9, $12,76]$. Equation 17 defines a simple way to calculate adhesion energy via the XDLVO theory [108].

$E_{\mathrm{XDLVO}}=E_{\text {Lifshitz-vdW }}+E_{\text {Electrostatic }}+E_{\text {Lewis-acid-base }}$
$E_{\mathrm{XDLVO}}$ describes the total energy of adhesion, while $E_{\text {Lifshitz-vdW }}, E_{\text {Electrostatic }}$, and $E_{\text {Lewis-acid-base }}$ are Lifshitz-van der Waals forces, electrostatic interactions, and Lewis acidbase forces, respectively [179]. The XDLVO theory is distance-dependent, too.

\section{Jet Cleaning-an Appropriate Solution for Filter Cloths}

The issue of insufficient cake discharges and the removal of remaining residues on the filter cloth have existed for decades. Many studies have shown suitable as well as improper techniques. Brush cleaning devices remove residues mechanically but can irreversibly damage the surface [99, 106]. Scraper blades also remove several residues by scratching on the filter surface [53]. Following Horrocks and Anand [66], they are jointly responsible for the abrasion of the filter cloth. The use of chemical agents - especially in the beverage industryoffers increased cleaning efficiency in addition to high microbiological safety. Agent utilization possibly damages filter cloths, however. The most commonly applied cleaning medium in the food industry is water, which adjusts agent concentration or acts as an autonomous mechanical cleaning tool [99].

Regarding the technique, jets are streamed mostly via nozzles onto soiled surfaces. In the beverage industry, this technology operates in many cleaning processes, e.g., cleaning in place (CIP) of tanks and pipe systems [52, 54, 99, 125, 160]. The cleaning of woven filter cloths includes the utilization of wash jets, too. Cleaning effects are impact forces and result in pressure distributions on the filter surface, which have to overcome the adhesive forces between the contamination and the filter cloth. The removability of residues using wash jets depends on four effects: direct residue deformation, stress wave creation and transfer, lateral outflow jetting, and hydraulic permeation in the soil layer $[15,54,110]$. Another advantage of wash jets is the adjustability of mechanical properties, e.g., nozzle geometry, pressure, fluid velocity, or incidence angle. This technique also combines the mechanical effect (kinetic energy) with the absorption of residues and their transport away from the contamination zone.

Agent-free cleaning is still not recommended, but cleaning with fewer agents and increased mechanical energy has

Table 6 Interactions and illustration of relevant adhesive forces and models

\begin{tabular}{lllll}
\hline Force & Distance $[\mathrm{nm}]$ & Strength $[\mathrm{kJ}]$ & Model & References \\
\hline Lifshitz-van der Waals & $0.3-0.4$ & $<2$ & Thermodynamic theory, DLVO theory, XDLVO theory & [150], [12], [149], [95], [108] \\
Electrostatic & Depends on media & DLVO theory, XDLVO theory & \\
Lewis acid-base & $0.2-0.3$ & $12-16$ & Thermodynamic theory, XDLVO theory & \\
\hline
\end{tabular}


become popular due to economic and ecological advantages. Besides, less cleaning agents or pure water cleaning decreases the risk of chemical soiling of beverages [114]. The easily adjustable combination of wash jets with specific temperature levels or adjusted $\mathrm{pH}$ values will have a positive synergetic effect on cleaning [129]. Therefore, wash jet techniques offer a demand-oriented setup for careful cleaning of filter cloths at a sufficient degree of cleaning. This section outlines the fluid mechanical properties and determination possibilities of wash jets and highlights their increased cleaning efficiency.

\section{Fluid Mechanical Principle of Wash Jets}

Following Fryer et al. [47], the understanding of fluid mechanical residue removal and its different realization possibilities are vital aspects for future research and developments for cleaning optimization. These aspects are also valid for wash jets, which have the potential to shorten cleaning time while reducing costs and sparing the environment. A nozzle always is in the responsibility of generating a cleaning jet. Here, static, static-dynamical, and dynamical systems are commercially available [52]. Following Mauermann [101] regarding cleaning processes, four different nozzle geometries are distinguishable:

- Flat jet nozzle

- Full/round jet nozzle

- Full cone nozzle

- Hollow cone nozzle

The nozzle geometry influences the acting forces and the corresponding area to be cleaned of the cloth (see Fig. 4). Out of this, the resulting pressure distribution and cleaning effect are derivable.

Cleaning jets released by nozzles are divisible into three distinct parts in terms of mechanical properties. The first part illustrates the nozzle leaving jet and its streaming into space (free jet). By impacting on filter surfaces, flow profiles change entirely due to complex filter geometries. The wash jet converts from a free jet (part one) to an impinging jet (part two). At the initial contact with the surface, wash jets distribute in different directions, which are almost parallel to the wall. The third part defines the behavior of absorbing contamination in the fluid. The absorption is an essential removal mechanism of the existing transportation streams and the flow-off of the impact area. Cleaning standards state that devoid of soil transportation by streams or jets cleaning processes would be insufficient [99]. Furthermore, the jet will also run partly through the filter mesh due to the distinct filter cloth porosity. Backflush cleaning uses this effect as an individual cleaning principle (see "The Process Design of Filter Cloth Cleaning with Jets" section).
Although all three fluid mechanical parts form one single jet, they are determinable independently. Tani and Komatsu [163] recognized that surfaces are not effecting on free jets about two jet diameters away from the surface, which is assumed to be the transition from free to impinging jet. In further research, Gauntner et al. [49] confirm the link of both parts by the definition of impinging jets having the same properties and behavior as free jets until the impact.

In every cleaning concept of wash jets, detailed knowledge about laminar or turbulent stream conditions is fundamental $[52,166]$. The Reynolds number $R e$ serves as a significant dimensionless quantity (Eq. 18) [137].

$\operatorname{Re}=\frac{v_{\mathrm{a}} \times d_{x}}{\vartheta}=\frac{\text { Inert force }}{\text { Friction force }}$

The variable $v_{\mathrm{a}}$ illustrates the average velocity, $d_{x}$ the characteristic diameter (e.g., particle diameter), and $\vartheta$ the kinematic viscosity. $R e$ classifies pipe or channel streams in three stream areas: laminar area $(R e \leq 2300)$, transition area $(2300$ $\left.\leq R e \leq 10^{4}\right)$, and turbulent region $\left(R e \geq 10^{4}\right)[146,157]$.

\section{Free Jet-Between the Nozzle and the Impact Zone}

Regarding surrounding conditions, a differentiation in onephase and two-phase jets is necessary. One-phase jetssubmerged jets - describe fluids that stream into a space filled with the same fluid. In general, wash jets, which are pure water or water mixed with cleaning agents in most cases, belong to the second group - the two-phase streams [64]. Here, jets exit a nozzle and impact on filter surfaces in an air-filled space.

The surrounding fluid profoundly influences many properties of free jets. Regarding classic free jets, the fluid streams into free space without any wall limitation. In the mist area between the streaming liquid and the surrounding medium, there are different velocities causing shear forces. Additionally, the different density and surface tension at the boundary layer of the two phases create turbulences, friction, and gas entrainment. The result is a jet break-up and an increasing jet decay in the axial direction. The appearance of this phenomenon and where it occurs highly depends on the nozzle geometry and operating pressure. Although this approach skips the direct jet impact on a wall to be cleaned, it is necessary to characterize the free jet properties, e.g., velocity gradients. Figure 5 illustrates the free jet while leaving a nozzle and streaming into space.

The literature $[49,105,121,161,162]$ shows several models to determine a two-phase free jet. Especially the core length and the velocity reduction in the axial $x$-direction are part of these approaches. In this publication, the free jet determinations by Gauntner et al. and Hrycak et al. are focused [49, 


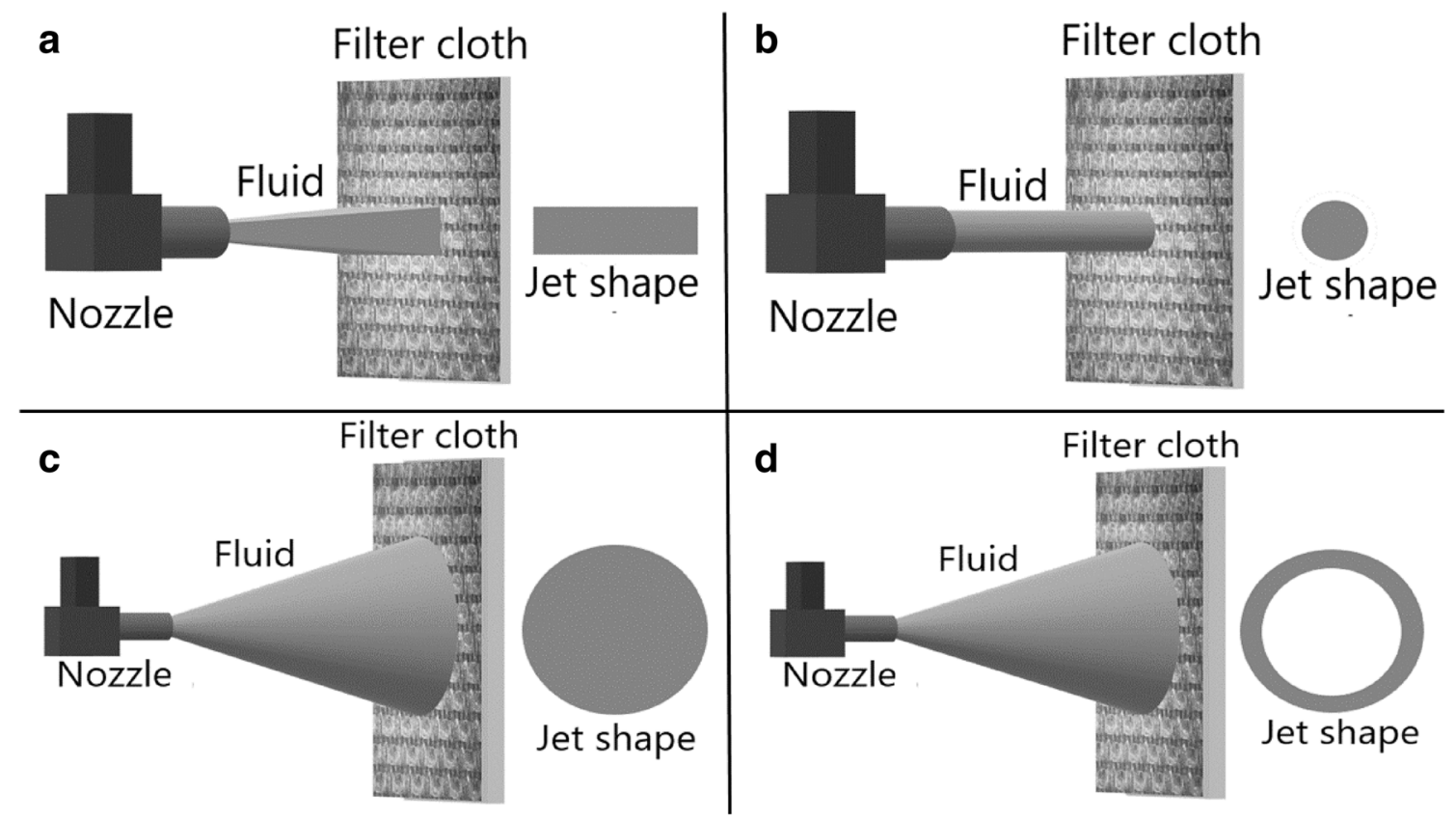

Fig. 4 Different nozzle geometries and the resulting impact area on the filter cloth: a flat jet nozzle, $\mathbf{b}$ full/round jet nozzle, $\mathbf{c}$ full cone nozzle, and $\mathbf{d}$ hollow cone nozzle; illustration is the authors' own creation and was inspired by Mauermann [101]

67] as it is the original method to determine a water jet in airfilled space. According to this approach, a classification of the flow profile of a jet into three distinct areas is necessary. Knowledge about these areas is essential to determine velocity and pressure conditions at specific stream points. These parameters are crucial for calculating the removal energy of the impinging jet.

Initial and Core Area-the Coherent Jet This area describes the flow of a jet from the nozzle and its dynamical establishment. It lasts from the nozzle to the apex of the potential core, which is the central part of the fluid. In the core area, velocity and several other parameters in the flow profile remain constant until the apex. By gaining distance from the nozzle, the core is decreasing due to the entrainment of the surrounding fluid. Mixing layers originate between the potential core and the surrounding fluid due to primary and secondary mass and momentum transfer effects (e.g., KelvinHelmholtz instabilities) [54]. This mixture of both fluids can be observed by a jet breaking up into droplets.

For complete descriptions of these two areas, the potential core length or nominal potential core length is decisive. According to the literature $[49,100]$, the core length depends on initial conditions and is four to six nozzle diameter long. However, core lengths are strongly dependent on the Reynolds number: In laminar streams, the range is proportional to the Reynolds number, while turbulent conditions are independent [67]. This aspect possibly results in enhanced and optimizable cleaning conditions. Velocities within the potential core depend on the nozzle diameter. Mass conservation (mass $M$ to time $t$ ) and continuity act between the nozzle $\dot{m}_{\text {Nozzle }}$ and connected pipe $\dot{m}_{\text {Pipe }}$ (Eq. 19) [11].

$\frac{\mathrm{d} M}{\mathrm{~d} t}=\dot{m}_{\text {Pipe }}-\dot{m}_{\text {Nozzle }}$

Subsequently, the integral form is obtained (Eq. 20).

$\int_{0}^{t} \rho \times A_{\text {Nozzle }} \times v_{\text {Nozzle }} \mathrm{d} t=\int_{0}^{t} \rho \times A_{\text {Pipe }} \times v_{\text {Pipe }} \mathrm{d} t$

By knowing $v_{\text {Nozzle }}$, nozzle area $A_{\text {Nozzle }}$, sectional pipe area $A_{\text {Pipe }}$, and regarding water as wash fluid with constant density $\rho$ over time, $v_{\text {Nozzle }}$ (velocity of the potential core at the centerline) is determinable with Eq. 21.

$v_{\text {Nozzle }}=\frac{A_{\text {Pipe }} \times v_{\text {Pipe }}}{A_{\text {Nozzle }}}$

Further, the relationship between $v_{\text {Nozzle }}$ and nozzle diameter $d_{\text {Nozzle }}$ is according to Eq. 22 (regarding round nozzles connected to pipes).

$v_{\text {Nozzle }}=\frac{d_{\text {Pipe }}^{2} \times v_{\text {Pipe }}}{d_{\text {Nozzle }}^{2}}$

Main Area-the Droplet Jet This central part of the free jet describes conditions after the potential core end. The jet 
Fig. 5 The path of a wash jet from the nozzle into the free space (free jet); variables: $v_{\text {Pipe }}=$ fluid velocity in the supply pipe; $v_{\text {Nozzle }}$ $=$ fluid velocity after the nozzle; $v_{\mathrm{C}, 2}=$ centerline velocity in the $x$ direction; $v_{x}=$ velocity at coordinate $x ; d_{\text {Pipe }}=$ pipe diameter; $d_{\text {Nozzle }}=$ nozzle diameter; the illustration is the authors' own creation and was adapted from Sigloch [153]

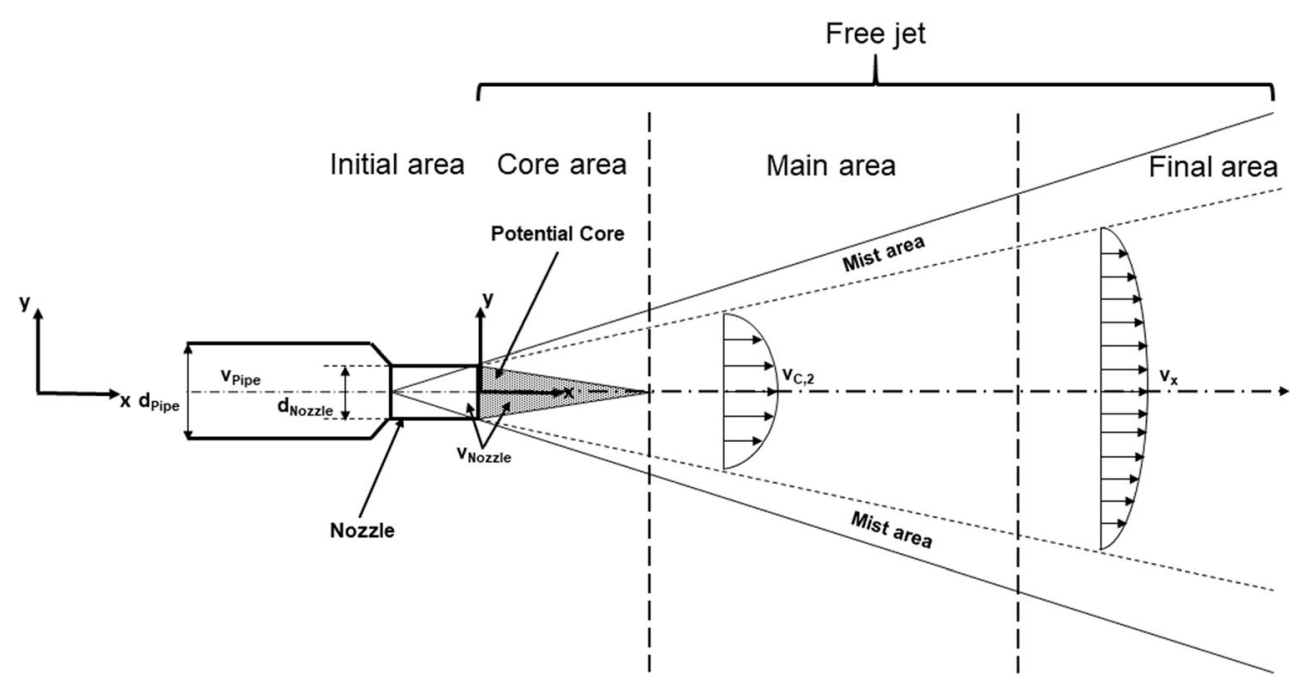

becomes broader and results in droplets due to the increased entrainment of the surrounding fluid and the already mentioned reasons. By momentum preservation, jet velocity decreases, which is describable by Gaussian curves [65]. The centerline velocity $v_{\mathrm{C}, 2}$ of area 2 is determinable via Eq. 23 [67].

$v_{\mathrm{C}, 2}=\frac{v_{\text {Nozzle }} \times l_{\text {Core }} \times d_{\text {Nozzle }}}{x}$

Here, variable $x$ defines the specific $x$-position, while $l_{\text {Core }}$ is the dimensionless potential core length. The mixture of jet and surrounding fluid results in larger droplets. The droplet size increases by gaining distance from the nozzle. The region nearest to the radial $x$-axis is named the water droplet zone, according to Guha et al. [54], while mixing zones of both phases are called mist areas due to the small droplet size.

Final Area-Atomized Jet The third and final area of a free jet is named the diffused droplet region [54]. Here, wash jets disintegrate fully and atomize into small droplets with negligible velocities. If distances between the nozzle and filter surface are too vast, the impact zone is in the diffused droplet region. As a result of this, contamination on filters is merely moistened but not cleaned away. The design of a cleaning concept has to consider a nozzle position close to the filter surface. The transition from the droplet jet to the atomized jet is determinable with the von-Ohnesorge number $(\mathrm{Oh})$, $R e$, and the von-Ohnesorge diagram [119].

Optimally, distances between nozzles and filter surfaces should be within the potential core or, at the least, the first part of area 2. On the one hand, the technical requirements do not always permit such close nozzle installations. On the other hand, too short distances between nozzle and surface end in jet rebounds, which result in flow blocks [54].

\section{Impinging Jet-Forces on the Residues on the Filter Cloth}

The impinging jet definition is a stream or a droplet that collides against a wall. After the collision, the jet is decelerated and deflected, while the kinetic energy resulting from the jet velocity is discharged to the filter cloth. The forces that are derivable from the energy result in a particular pressure distribution that creates impulses as well as wall shear stress on the filter cloth. The combination of different hydraulic effects finally cares for the cleaning effect. The changeover from the free jet observation to the impinging part is within a short distance from the surface. Leach et al. [90] showed that by using surface cutting water jets, fluid pressure became equal to the pressure of the surrounding fluid in distances of 1.3 . $d_{\text {Nozzle }}$ (nozzle diameter) from the impact point due to less shear stress. In newer studies, Guha et al. [54] determined distances up to $1.68 \cdot d_{\text {Nozzle }}$. However, this parameter is strongly dependent on nozzle and fluid properties. The impingement of a jet can be categorized in different areas, as shown in Fig. 6.

Area of Impingement Before the collision, the jet has an absolute velocity (see free jet calculation) and kinetic energy. Here, forces result in effecting the contamination on the surface. The wall shear stress $\tau$ dominates direct mechanical effects on filter cloths (see Eq. 24), which has a cleaning impact due to the inner friction of real fluids [30, 46, 70].

$\tau=\frac{F}{A}$

$F$ is the effecting force, while $A$ is the corresponding area. However, it is necessary to consider that it is not the actual force that is responsible for cleaning in the impact area. Instead, the resulting occurrence of pressures and their distribution on the cloth gives the cleaning effect [105]. By 
collision with the filter cloth, the jet fluids are compressed, which results in pressures affecting the surface in a time interval $<1 \mathrm{~ms}$ [101]. At the boundary layer to the soiled filter cloth, shock waves act equally to the surface and against the jet direction $[2,3,153]$. The resulting pressure distribution undergoes a reduction in the inner part of the contact zone to the normal water hammer pressure. After a particular streaming time, the jet stabilizes, and a dynamic pressure effect on the filter cloth acts. For this quasistatic effect, a coherent jet with a specific flowing time is necessary.

Radial Flow Area-the Lateral Drainage of the Cleaning Fluid After impacting on the filter cloth, the liquid is drained off around the impingement area almost symmetrically. Impacting jets are slowed down in the axial direction and accelerated in the radial direction in the eddy area. At the impact point, the fluid velocity is even zero [65]. Therefore, the radial flow is also responsible for detachment of soil, which can even reach higher speeds than the jet velocity [105]. Wilson et al. [178] also defined this area as a radial flow zone (RFZ). Knowledge about the distribution (backflow) of jets after impacting on filter surfaces is essential due to cleaning efficiency and sufficient transport of product residues away from filter cloths. Siekmann and Thamsen [152] define the backflow effect $\epsilon_{\text {Fluid }}$ with Eq. 25 . Figure 6 shows the distribution of the jet and the resulting mass transfers.

$\epsilon_{\text {Fluid }}=\frac{\dot{m}_{2}}{\dot{m}_{1}}$

The variable $\epsilon_{\text {Fluid }}$ is the backflow coefficient, $\dot{m}_{1}$ is the mass flow of the fluid after the nozzle, and $\dot{m}_{2}$ is the mass flow of the deflected jet. Regarding a distributed stream in two directions, the following context is valid (Eqs. 26-27).

$\dot{m}_{3}=\dot{m}_{1} \times \varepsilon_{\text {Fluid }}$
$\dot{m}_{2}=\dot{m}_{1} \times\left(1-\varepsilon_{\text {Fluid }}\right)$

Here, $\dot{m}_{3}$ is the second deflected jet after the impact. As can be seen, backflow is irrespective of jet velocity. Here, the most influencing factor is the incidence angle. If increased, fluids will stream in almost equal parts in both directions. It is concludable that angled jet incidents toward the filter surface are an essential parameter and always require incorporation in cleaning concept planning.

Transition Area Direct after the impingement and within the radial flow zone, Wilson et al. describe the formation of a thin liquid layer [178]. This boundary layer is observable from the filter cloth until the layer between the liquid and the surrounding gas phase (e.g., air). Within this small layer, the stream along the filter cloth is laminar. After a certain distance, the distinctive film jump takes place where an arching of the liquid changes the flow properties to turbulent. The reason for this effect is derivable from the balanced outward momentum before the jump, which is caused by the surface tension between the two phases [16].

Regarding a full/hollow cone or a round jet nozzle, this jump is a circular ring around the impingement area. Concerning filter cloths, this jump depends on the turbulence condition and the type of fixing of the filter cloth in the filter apparatus. If the cloth is not tensioned enough, the softness reduces this effect, as the jet may press the cloth too much. Concluding, the boundary layer thickness $\delta$ is a decisive parameter for determining the velocity decreasing effect and friction in this layer [46]. The thickness can be determined by Eq. 28 for laminar and turbulent conditions [83].

$$
\begin{aligned}
\delta_{\text {laminar }}(x) & =\frac{4.9 \times x}{\sqrt{\mathrm{Re}_{x}}} \\
\delta_{\text {turbulent }}(x) & =\frac{0.37 \times x}{\operatorname{Re}_{x}^{0.2}}
\end{aligned}
$$

Determination of Acting Forces Impinging jets are difficult to predict and calculate due to existing turbulences and different flow profiles. Impulse, pressure, wall, and other forces, which are acting directly on impact areas, are discoverable via the momentum conservation principle. Entering and leaving impulse streams in self-contained fluid spaces are balanced in every coordination direction. A possible approach to determine forces of a jet impacting on a surface is findable in the literature $[37,61,118,153]$. Firstly, the impulse equation serves as a point of origin (Eq. 29).

$\rho A c^{2}+\sum F=0$

With the impulse equation, different fluid mechanical influences become clear for Newtonian fluids (e.g., wash water in jets). The differential form is the base of the determination (Eq. 30).

$\rho\left(\frac{\mathrm{d} v_{j}}{\mathrm{~d} t}+v_{i} \frac{\mathrm{d} v_{j}}{\mathrm{~d} x_{i}}\right)=-\frac{\mathrm{d} p}{\mathrm{~d} x_{j}}-\frac{\mathrm{d} \tau_{i j}}{\mathrm{~d} x_{i}}+\rho g_{j}$

The variable $p$ presents the pressure, $t$ is the time, and $g$ is the gravity acceleration constant. Integration over a control volume and addition of continuity equation results in Eq. 31 .

$$
\begin{aligned}
\int_{V_{C}} \frac{d \rho v_{j}}{\mathrm{~d} t} \mathrm{~d} V+\int_{A_{C}} \rho v_{i} v_{j} \mathrm{~d} A_{i}= & -\int_{A_{C}} p \mathrm{~d} A_{j}-\int_{A_{C}} \tau_{i j} \mathrm{~d} A_{i} \\
& +\int_{V_{C}} \rho g_{j} \mathrm{~d} V+\sum F_{j}
\end{aligned}
$$

The impulse equation was transferred and simplified in the Euler equation for fluid mechanical models (Eq. 32) [11, 31, 89]. Here, neglect of liquid friction, as well as viscosity, and consideration of elastic fluids within the stream are necessary. 
Fig. 6 Vertical impinging $(\alpha=$ $90^{\circ}$ ) and transport jet with corresponding jet areas (example: filter cloth in a vertical, most common position like in filter presses). $\dot{m}_{1}=$ entire mass flow impacting on the surface; $\dot{m}_{2}=$ portion of the mass flow in the negative $y$-direction; $\dot{m}_{3}=$ portion of the mass flow in the positive $y$ direction; $g=$ acceleration of gravity constant; the illustration is the authors' own creation and was adapted from Siekmann and Thamsen [152], Wilson et al. [178], and Bhagat and Wilson [16]

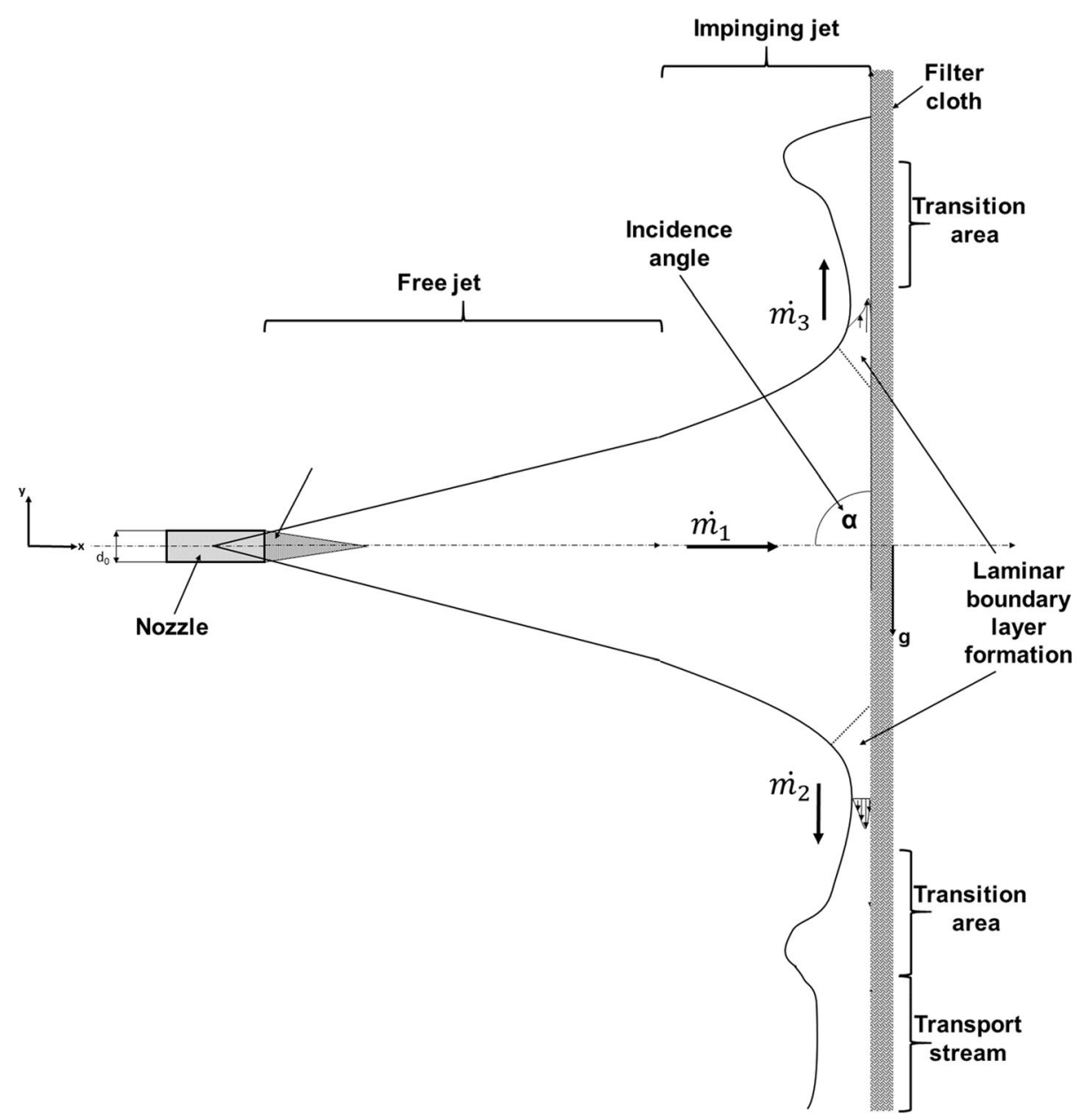

$\rho\left(\frac{\mathrm{d} v_{j}}{\mathrm{~d} t}+v_{i} \frac{\mathrm{d} v_{j}}{\mathrm{~d} x_{i}}\right)=-\frac{\mathrm{d} p}{\mathrm{~d} x_{j}}+\rho g_{j}$

The further advanced Navier-Stokes equation (Eq. 33) respects viscosity [146, 159].

$\rho\left(\frac{\mathrm{d} v_{j}}{\mathrm{~d} t}+v_{i} \frac{\mathrm{d} v_{j}}{\mathrm{~d} x_{i}}\right)=-\frac{\mathrm{d} p}{\mathrm{~d} x_{j}}+\mu \frac{\mathrm{d}^{2} v_{j}}{\mathrm{~d} x_{i}^{2}}+\rho g_{j}$

In general, the assumption is necessary that high fluid pressures result in high jet velocities, which will favor the cleaning effect. However, attention has to be paid to the damaging effect of high pressures toward filter cloths. Furthermore, forceful impacts also benefit aerosol distribution and the unwanted re-soiling of filter cloths [157]. According to the literature [41], minimum pressure has to range between 3 and 5 bar, while jet speed has to be 3 to $4 \mathrm{~m} / \mathrm{s}$.

\section{Transport Stream—Removing Detached Residues}

Cleaning processes are ineffective without complete removal of the contamination. Therefore, it is necessary to observe the liquid film that runs off. Concerning the stream condition, turbulent flows favor cleaning due to a considerable soil retention capacity and increased wall shear stress [166]. Due to inconsistent axial velocity and resulting transverse flows, the fluids, which absorbed already a soil quantity, are mixed in the turbulent stream [128]. Particular forms of the impulse equation also conduct the determination of transport streams. Creeping flows describe streams with small Reynolds numbers, where viscosity forces are more influential than acceleration forces. The Navier-Stokes equation serves as the origin of the approach to determine the velocity of certain areas in the flow profile of a transport stream [118]. Equation 34 is applicable when observing laminar film flows on even surfaces [154].

$\frac{\Delta p}{L}=\mu \frac{d^{2} v_{1}}{\mathrm{~d} x_{2}^{2}}+\rho g_{1}$

In contrast, boundary layer flows are valid for streams with high Reynolds numbers. For careful considerations, accurate measurements, in addition to numerical methods, have to be performed. 
Fig. 7 Concepts for cleaning filter media with wash jets. a Forward flush cleaning. b Backflush cleaning. The illustration is the authors' own creation

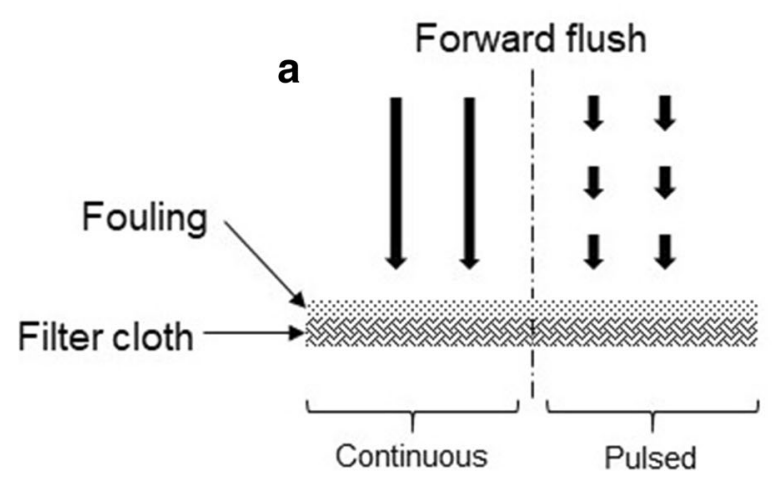

\section{The Process Design of Filter Cloth Cleaning with Jets}

The literature concludes that cleaning fluid velocity is one of the most important parameters [78, 160]. For cleaning of technical surfaces consisting of stainless steel or other metals, the range of jet velocity should be between 80 and $200 \mathrm{~m} / \mathrm{s}$ [54]. However, this speed is often too high for interweaved sensitive textiles like filter cloths. Furthermore, filter fabrics are stretched by impacting jets that additionally increase pressure and stress on the material and weave. The design of the cleaning process also is vital in choosing the right cleaning concept. Here, continuous jet cleaning via forward flush or backflush is state of the art. Alternative ideas, e.g., pulsatile jets, have been developed in the last years.
The big difference between forward flush and backflush is the jet direction to the filter (see Fig. 7). While forward flushes are contacting contamination directly, backflushes reach residues on filter cloths after crossing the whole filter cloth. Therefore, forward flushes unfold their full pressure completely onto adhering residues, while backflushes reach the contaminated areas with modified energy and even avoid contamination in stream shadows. On the other hand, forward techniques press residues deeper into the filter cloth, while backwashing provides full transport - if reachable - away from the filter. The selection of the right cleaning concept in terms of the suitability depends strongly on the filter type, weave, construction, material, and product.
Fig. 8 Illustration of the fluid velocity of a jet with two pulses and one pause; the illustration is the authors' own creation

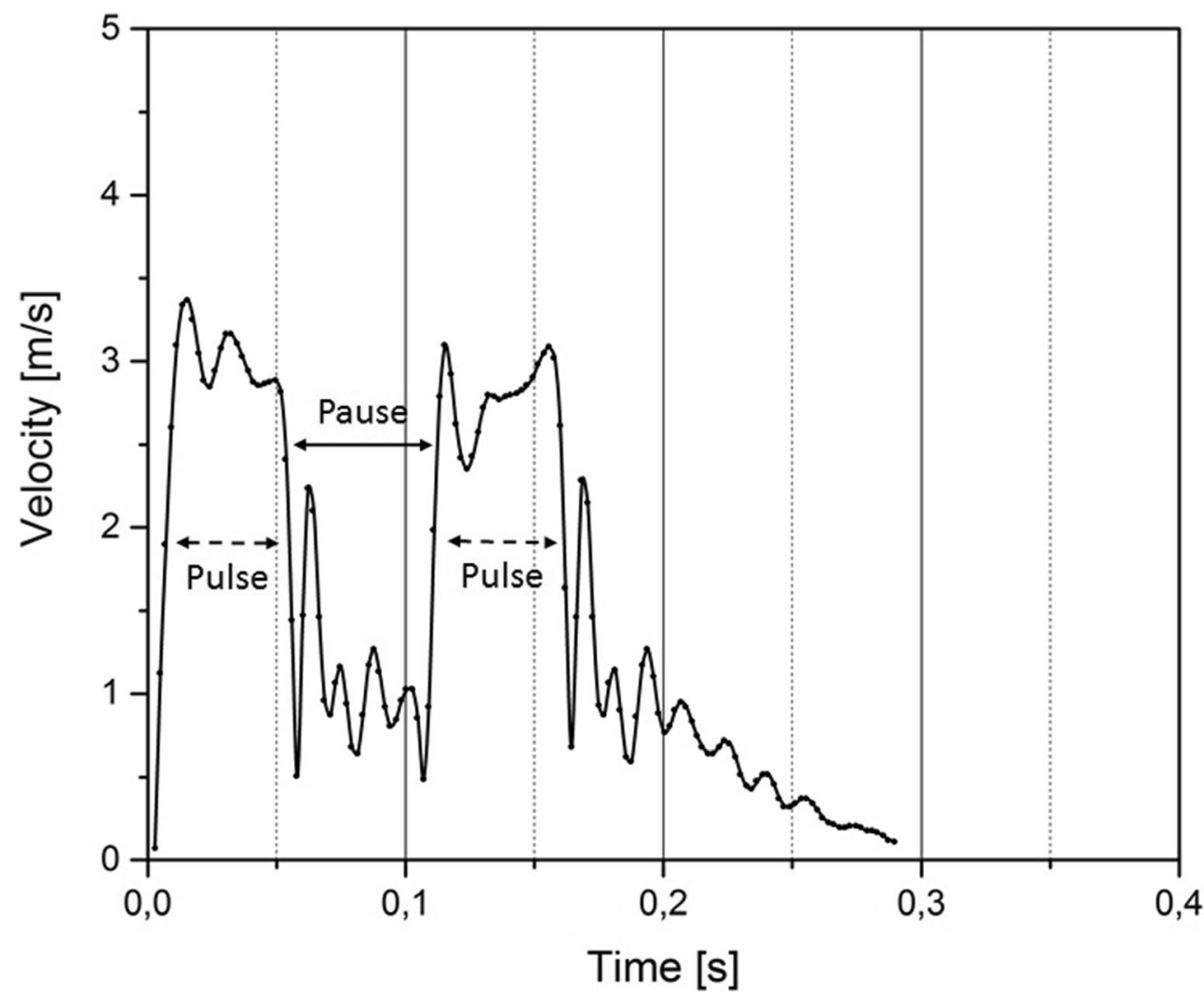


Fig. 9 Influencing factors for filter media cleaning; the illustration is the authors' own creation

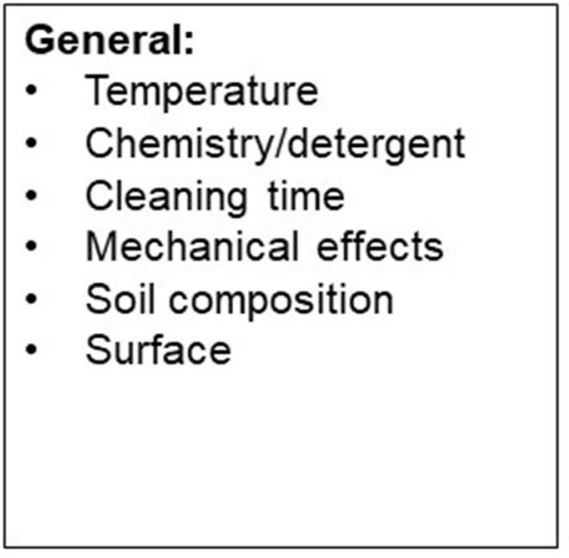

Filter media parameter:

- Material

- Construction

- Finish

- Product composition

- Detergent

- Costs (systems, detergents, life span of cloths)

- Technical requirements

\section{Detergent cleaning:}

- Type and amount of soil

- Detergent type

- Concentration

- Surface properties

- Surface Material

- Economy and costs

- Ecologic aspects

\section{Continuous Wash Jet}

A simple way to use wash jets for filter cloth cleaning is to stream them continuously onto the surface or to backflush them. As a result of this, jets are focused on the area to be cleaned. They have direct contact with residues, which results in immediate force effects (conservation of the momentum). Although many different applications are using continuous wash jets in various cleaning units, there is only a little research concerning filter cloth cleaning. Initial investigations in cleaning filter media were performed by Stahl et al. [155] in observing particle-loaded filter media. Furthermore, they calculated stream and wall shear stress distributions of woven filter media and identified low wall shear stressed areas. Weidemann [173] observed the cleaning kinetics of different filter cloths using model contaminations. The results showed a high dependency on cleaning velocity, filter roughness, and weave type. Ulmer [166] developed a cleaning model for filter media, where a layer with versatile particles originated after residue detachment resulting in equilibrium concentrations. Mass transport between equilibrium layers and fluid streams ensures contamination transport away from the surfaces. However, the thickness of the equilibrium layers depends on fluid velocity.
Pulsatile Wash Jet

Pulsatile jets depict non-continuous streams on filter media. With this, the cleaning jet divides into several jet intervals that subdivide into pulse length and pulse pause (Fig. 8). Pulsatile cleaning has been investigated for many different applications in the beverage and food industries [22, 38, 43, 46, 51]. The advantages of this concept were verified in cleaning elbows and straight pipes [8, 18, 19, 44]. Trials using pulsatile cleaning for filter media were conducted with bag filters and dust removal [66, 88, 97, 164, 165].

Generally, cleaning efficiency increases by using higher stream velocities due to higher wall shear stress. However, in most cases, an increase in cleaning speed is only reasonable using pulsatile applications (e.g., fluid consumption, too strong continuous impulses). Due to the desired reduction of liquid mass, initial investigations in cleaning filter media with pulsatile jets via backflush were performed by Weidemann et al. $[93,173,174]$. The cleaning results showed 1.5 higher cleaning degrees compared to continuous wash jets. Werner et al. [176] extended the investigations on forward flush cleaning. They showed the suitability of pulsatile jets in comparison to backwashing or continuous cleaning by removing yeast cells from filter cloths. The advantages of this promising 
concept are the reduction of cleaning fluid and higher cleaning degrees.

The increased cleaning performance is related to higher wall shear stress by pulsating wash jets and waviness onto the surface, which also decreases boundary layers [8]. The effect of acting shock waves and water hammer pressures within the first microsecond of the jet impingement can also be used by pulsed jet cleaning more efficiently [153]. Another effect is fluid drainage between two jets and the joint removal of cushioning liquid layers on filter surfaces. Subsequent jets can unfold their pressure on contamination due to direct contact fully. Furthermore, pulsatile jet cleaning also enhances the cleanability of difficult-to-clean areas [44]. From an ecological and economic point of view, as well as regarding cleaning efficiency, pulsatile jet cleaning is the most promising method for filter fabrics. Cleaning in both directions offers appropriate cleaning results, even if direct contact of the wash jet with residues is preferable due to higher affecting forces.

\section{Conclusion}

This paper outlined the cleaning challenges of woven filter cloths in detail. Besides the cleaning limitation due to the material properties of cloths (e.g., temperatures, cleaning agents, and sanitizers), the complexity of the filter structures hinders cleaning. Designed for efficient filtration processes, the rough topographies of filter cloth contradict any regulations and design features in terms of hygienic design. Furthermore, involved beverage residues that adhere heterogeneously on filter cloth increase this problematic situation. For a sufficient cleaning efficiency, the cleaning mechanism has to overcome the adhesive forces between the soil and surface. This paper showed here the relevant biophysical interactions in order to show the necessities of a sufficient cleaning concept. Finally, water jet cleaning highlights as the cleaning method with the most significant and most optimizable cleaning effect.

The main advantage is the easy adjustability and flexibility of new products. Wash jets are categorizable into three different areas: free jet, impinging jet, and the transport stream of residues. Here, the distance between the nozzle and filter surface and nozzle geometries are critical aspects for the determination of optimal cleaning concepts.

Regarding the fluid mechanical properties, stream velocity and the resulting wall shear stress on the residues are central. The integration of these aspects into the design of the cleaning process is crucial. Neglect of chemical agents is not possible due to high hygienic standards. However, economic and ecological aims negate a further increase in chemicals or temperature in future research. Here, the mechanical effects of wash jets need to be in focus. Previous studies confirmed pulsed jets as a promising method and advantageous for filter cloth.
The aim of complete cake discharges and a fully automated filtration process is the focus of research for decades. The goals of efficient cleaning concepts are short filter downtimes, prevention of cross-contamination, high product safety, and economic and ecologic aspects (e.g., cleaning agent reduction). Besides, filter cloths require considerately and function-retaining treatment to ensure long service life. Jet cleaning can be a milestone that may reach these goals in combination with adequate sensor techniques and demandoriented cleaning [107]. For finding the right procedure, Fig. 9 illustrates possible ways for filter cloth cleaning.

Authors' Contributions Werner, R. A.: main author, literature research and review, executing scientist, writing of the publication. Geier, D. U.: corresponding author, critical content review. Becker, T.: project supervision, critical review.

Funding Information Open Access funding provided by Projekt DEAL. This IGF Project 19716 N of the IVLV (Industrievereinigung für Lebensmitteltechnologie und Verpackung e.V., Freising, Germany) is supported via $\mathrm{AiF}$ within the program for promoting the Industrial Collective Research (IGF) of the German Ministry of Economic Affairs and Energy (BMWi), based on a resolution of the German Parliament.

\section{Compliance with ethical standards}

Conflict of Interest The authors declare that they have no conflict of interest.

Open Access This article is licensed under a Creative Commons Attribution 4.0 International License, which permits use, sharing, adaptation, distribution and reproduction in any medium or format, as long as you give appropriate credit to the original author(s) and the source, provide a link to the Creative Commons licence, and indicate if changes were made. The images or other third party material in this article are included in the article's Creative Commons licence, unless indicated otherwise in a credit line to the material. If material is not included in the article's Creative Commons licence and your intended use is not permitted by statutory regulation or exceeds the permitted use, you will need to obtain permission directly from the copyright holder. To view a copy of this licence, visit http://creativecommons.org/licenses/by/4.0/.

\section{References}

1. Adair JH, Suvaci E, Sindel J (2001) Surface Colloid Chem:1-10. https://doi.org/10.1016/B0-08-043152-6/01622-3

2. Aganin A, Guseva T (2019) Numerical simulation of liquid mass collision with a wall. Progress Comput Fluid Dyn 19(5):293. https://doi.org/10.1504/PCFD.2019.102058

3. Aganin A, Guseva T (2020) Liquid jet impact on a wet wall. European Journal of Mechanics - B/Fluids 79:141-150. https:// doi.org/10.1016/j.euromechflu.2019.09.001

4. Anand S, Singh D, Avadhanula M, Marka S (2014) Development and control of bacterial biofilms on dairy processing membranes. Compr Rev Food Sci Food Saf 13(1):18-33. https://doi.org/10. $1111 / 1541-4337.12048$ 
5. Anlauf H (2007) Filtermedien zur Kuchenfiltration - Schnittstelle zwischen Suspension und Apparat. Chemie Ingenieur Technik 79(11):1821-1831. https://doi.org/10.1002/cite.200700093

6. Anlauf H (2019) Wet cake filtration. Fundamentals, equipment, strategies. Wiley-VCH, Weinheim

7. Annemüller G, Manger H-J, Lietz P (2011) The yeast in the brewery. Management - pure yeast cultures - propagation, 1. Ed. VLB manuals. VLB, Berlin

8. Augustin W, Fuchs T, Föste H, Schöler M, Majschak J-P, Scholl S (2010) Pulsed flow for enhanced cleaning in food processing. Food Bioprod Process 88(4):384-391. https://doi.org/10.1016/j. fbp.2010.08.007

9. Azeredo J, Visser J, Oliveira R (1999) Exopolymers in bacterial adhesion. Interpretation in terms of DLVO and XDLVO theories. Colloids Surf B: Biointerfaces 14(1-4):141-148. https://doi.org/ 10.1016/S0927-7765(99)00031-4

10. Back W (ed) (2008) Ausgewählte Kapitel der Brauereitechnologie, 2nd edn. Nürnberg, Fachverlag Hans Carl

11. Batchelor GK, Batchelor GK (2000) An introduction to fluid dynamics, 2nd edn. Cambridge University Press, Cambridge

12. Bayoudh S, Othmane A, Mora L, Ben Ouada H (2009) Assessing bacterial adhesion using DLVO and XDLVO theories and the jet impingement technique. Colloids and Surfaces. B, Biointerfaces 73(1):1-9. https://doi.org/10.1016/j.colsurfb.2009.04.030

13. Berk Z (ed) (2013) Food process engineering and technology, 2nd edn. Amsterdam, Academic

14. Bessada R, Silva G, Paiva MC, Machado AV (2011) Functionalization of PET and PA6.6 woven fabrics. Appl Surf Sci 257(18):7944-7951. https://doi.org/10.1016/j.apsusc.2011. 04.002

15. Beutin EF (1975) Flüssigkeitsschlag, Grundlagen der Beanspruchung und ihre technische Nutzanwendung. Dissertation, Technical University of Hannover

16. Bhagat RK, Wilson DI (2016) Flow in the thin film created by a coherent turbulent water jet impinging on a vertical wall. Chem Eng Sci 152:606-623. https://doi.org/10.1016/j.ces.2016.06.011

17. Biswas P, Bandyopadhyaya R (2017) Biofouling prevention using silver nanoparticle impregnated polyethersulfone (PES) membrane: E. coli cell-killing in a continuous cross-flow membrane module. J Colloid Interface Sci 491:13-26. https://doi.org/10. 1016/j.jcis.2016.11.060

18. Blel W, Le Gentil-Lelièvre C, Bénézech $\mathrm{T}$, Legrand $\mathrm{J}$, Legentilhomme P (2009a) Application of turbulent pulsating flows to the bacterial removal during a cleaning in place procedure. Part 1. Experimental analysis of wall shear stress in a cylindrical pipe. J Food Eng 90(4):422-432. https://doi.org/10.1016/j. jfoodeng.2008.07.008

19. Blel W, Legentilhomme P, Bénézech T, Legrand J, Le GentilLelièvre C (2009b) Application of turbulent pulsating flows to the bacterial removal during a cleaning in place procedure. Part 2. Effects on cleaning efficiency. J Food Eng 90(4):433-440. https://doi.org/10.1016/j.jfoodeng.2008.07.019

20. Bobe U (2008) Die Reinigbarkeit technischer Oberflächen im immergierten System. Dissertation, Technische Universität München

21. Bobe U, Hofmann J, Sommer K, Beck U, Reiners G (2007) Adhesion - where cleaning starts. Trends Food Sci Technol 18: S36-S39. https://doi.org/10.1016/j.tifs.2006.10.019

22. Bode K, Hooper RJ, Paterson WR, Ian Wilson D, Augustin W, Scholl S (2007) Pulsed flow cleaning of whey protein fouling layers. Heat Transfer Eng 28(3):202-209. https://doi.org/10. 1080/01457630601064611

23. Boks NP, Kaper HJ, Norde W, van der Mei HC, Busscher HJ (2009) Mobile and immobile adhesion of staphylococcal strains to hydrophilic and hydrophobic surfaces. J Colloid Interface Sci 331(1):60-64. https://doi.org/10.1016/j.jcis.2008.11.025
24. Bowen WR, Jenner F (1995) The calculation of dispersion forces for engineering applications. Adv Colloid Interf Sci 56:201-243. https://doi.org/10.1016/0001-8686(94)00233-3

25. Brennan JG (2012) Food processing handbook, 2nd edn. Wiley$\mathrm{VCH}$, Weinheim

26. Brunette DM (2001) Principles of cell behavior on titanium surfaces and their application to implanted devices. Titanium in Medicine. Engineering Materials.:485-512. https://doi.org/10. 1007/978-3-642-56486-4 15

27. CAMPUS - Computer Aided Material Preselection by Uniform Standards (2020) Material information system for the plastics industry. https://www.campusplastics.com. Accessed 07 Mar 2020

28. Cassano A, Conidi C, Drioli E (2013) Membrane processing. Dairy and beverage applications, Wiley-Blackwell, Chichester

29. Chan R, Chen V (2001) The effects of electrolyte concentration and $\mathrm{pH}$ on protein aggregation and deposition. Critical flux and constant flux membrane filtration. J Membr Sci 185(2):177-192. https://doi.org/10.1016/S0376-7388(00)00645-1

30. Cheow CS, Jackson AT (1982) Circulation cleaning of a plate heat exchanger fouled by tomato juice. Int J Food Sci Technol 17(4): 431-440. https://doi.org/10.1111/j.1365-2621.1982.tb00198.x

31. Chorin AJ, Marsden JE (2000) A mathematical introduction to fluid mechanics, vol 4, 3rd edn. Springer, New York

32. Colmenares JC, Kuna E, Jakubiak S, Michalski J, Kurzydłowski $\mathrm{K}$ (2015) Polypropylene nonwoven filter with nanosized $\mathrm{ZnO}$ rods: promising hybrid photocatalyst for water purification. Appl Catal B Environ 170-171:273-282. https://doi.org/10.1016/j. apcatb.2015.01.031

33. Cox MF (1986) Surfactants for hard-surface cleaning: mechanisms of solid soil removal. J Am Oil Chem Soc 63(4):559-565. https://doi.org/10.1007/BF02645756

34. Davey KR, Chandrakash S, O'Neill BK (2015) A Friday 13th failure assessment of clean-in-place removal of whey protein deposits from metal surfaces with auto-set cleaning times. Chem Eng Sci 126:106-115. https://doi.org/10.1016/j.ces.2014.12.013

35. Derjaguin B, Landau L (1993) Theory of the stability of strongly charged lyophobic sols and of the adhesion of strongly charged particles in solutions of electrolytes. Prog Surf Sci 43(1-4):30-59. https://doi.org/10.1016/0079-6816(93)90013-L

36. Drioli E, Giorno L (eds) (2016) Encyclopedia of membranes. Springer, Berlin

37. Durst F (2006) Grundlagen der Strömungsmechanik. Eine Einführung in die Theorie der Strömung von Fluiden. Springer, Berlin

38. Edwards M, Wilkinson W (1971) Review of potential applications of pulsating flow in pipes. Trans Inst Chem Eng 49(2):85-94

39. Ehlers S (1961) The selection of filter fabrics re-examined. Ind Eng Chem 53(7):552-556. https://doi.org/10.1021/ie50619a024

40. El Rayess Y, Albasi C, Bacchin P, Taillandier P, Raynal J, Mietton-Peuchot M, Devatine A (2011) Cross-flow microfiltration applied to oenology: a review. J Membr Sci 382(1-2):1-19. https://doi.org/10.1016/j.memsci.2011.08.008

41. Esslinger HM (2009) Handbook of brewing. Processes, technology, markets. Wiley-VCH, Weinheim

42. Filali L, Brahmi Y, Sib JD, Bouhekka A, Benlakehal D, Bouizem Y, Kebab A, Chahed L (2016) The effect of amorphous silicon surface hydrogenation on morphology, wettability and its implication on the adsorption of proteins. Appl Surf Sci 384:107-115. https://doi.org/10.1016/j.apsusc.2016.05.013

43. Förster M, Augustin W, Bohnet M (1999) Influence of the adhesion force crystal/heat exchanger surface on fouling mitigation. Chem Eng Process Process Intensif 38(4-6):449-461. https://doi. org/10.1016/S0255-2701(99)00042-2

44. Föste H, Wesche M, Kücke M, Augustin W, Scholl S, Helbig M, Majschak J-P (2014) Pulsierende Strömung. Ressourceneffiziente 
Cleaning-in-Place-Reinigung. Chemie Ingenieur Technik (CIT plus) 17(12):50-52

45. Fryer PJ, Asteriadou K (2009) A prototype cleaning map: a classification of industrial cleaning processes. Trends Food Sci Technol 20(20):255-262. https://doi.org/10.1016/j.tifs.2009.03. 005

46. Fryer PJ, Christian GK, Liu W (2006) How hygiene happens: physics and chemistry of cleaning. Int J Dairy Technol 59(2): 76-84. https://doi.org/10.1111/j.1471-0307.2006.00249.x

47. Fryer PJ, Robbins PT, Asteriadou K (2011) Current knowledge in hygienic design. Can we minimize fouling and speed cleaning? Proc Food Sci 1:1753-1760. https://doi.org/10.1016/j.profoo. 2011.09.258

48. Gan Q, Field RW, Bird MR, England R, Howell JA, McKechnie MT, O'Shaughnessy CL (1997) Beer clarification by cross-flow microfiltration: fouling mechanisms and flux enhancement. Chem Eng Res Des 75(1):3-8. https://doi.org/10.1205/ 026387697523327

49. Gauntner JW, Livingood JNB, Hrycak P (1970) Survey of literature on flow characteristics of a single turbulent jet impinging on a flat plate. Technical report (NASA-TN-D-5652, E-5203). https:// ntrs.nasa.gov/archive/nasa/casi.ntrs.nasa.gov/19700009658.pdf. Accessed 17 May 2020

50. Gerhards C, Schramm M, Schmid A (2019) Use of the Weibull distribution function for describing cleaning kinetics of high pressure water jets in food industry. J Food Eng 253:21-26. https://doi. org/10.1016/j.jfoodeng.2019.02.011

51. Gillham CR, Fryer PJ, Hasting APM, Wilson DI (2000) Enhanced cleaning of whey protein soils using pulsed flows. J Food Eng 46(3):199-209. https://doi.org/10.1016/S0260-8774(00)00083-2

52. Goode KR, Asteriadou K, Robbins PT, Fryer PJ (2013) Fouling and cleaning studies in the food and beverage industry classified by cleaning type. Compr Rev Food Sci Food Saf 12(2):121-143. https://doi.org/10.1111/1541-4337.12000

53. Groysman A (ed) (2017) Corrosion problems and solutions in oil refining and petrochemical industry, 1, Ed., vol, vol 32. Springer, Cham

54. Guha A, Barron RM, Balachandar R (2011) An experimental and numerical study of water jet cleaning process. J Mater Process Technol 211(4):610-618. https://doi.org/10.1016/j.jmatprotec. 2010.11.017

55. Guo J, Sotto A, Martín A, Kim J (2017) Preparation and characterization of polyethersulfone mixed matrix membranes embedded with Ti- or Zr-incorporated SBA-15 materials. J Ind Eng Chem 45:257-265. https://doi.org/10.1016/j.jiec.2016.09.033

56. Hamaker HC (1937) The London - van der Waals attraction between spherical particles. Physica 4(10):1058-1072. https://doi. org/10.1016/S0031-8914(37)80203-7

57. Hardman E (1994) Some aspects of the design of filter fabrics for use in solid/liquid separation processes. Filtr Sep 31(8):813-806. https://doi.org/10.1016/0015-1882(94)80539-3

58. Hauser G (2008) Hygienische Produktionstechnologie. Wiley$\mathrm{VCH}$, Weinheim

59. Haynes CA, Norde W (1994) Globular proteins at solid/liquid interfaces. Colloids Surf B: Biointerfaces 2(6):517-566. https:// doi.org/10.1016/0927-7765(94)80066-9

60. Heisenberg W (1927) Ueber den anschaulichen Inhalt der quantentheoretischen Kinematik und Mechanik. Z Phys 43(3-4): 172-198. https://doi.org/10.1007/BF01397280

61. Herwig H (2008) Strömungsmechanik. Einführung in die Physik von technischen Strömungen, 1st edn. Vieweg+Teubner, Wiesbaden

62. Hmidet N, El-Hadj Ali N, Haddar A, Kanoun S, Alya S-K, Nasri $\mathrm{M}$ (2009) Alkaline proteases and thermostable $\alpha$-amylase co-produced by Bacillus licheniformis NH1. Characterization and potential application as detergent additive. Biochem Eng J 47(13):71-79. https://doi.org/10.1016/j.bej.2009.07.005

63. Hoffmann W, Reuter H (1984) Zirkulationsreinigen (CIP) von geraden Rohren in Abhängigkeit von der Oberflächenrauheit und anderen Einflußfaktoren. Chemie Ingenieur Technik 56(4): 328-329. https://doi.org/10.1002/cite.330560419

64. Hofmann HA (2005) Wärmeübergang beim pulsierenden Prallstrahl. Dissertation, Universität Karlsruhe (TH)

65. Hofmann HM, Kaiser R, Kind M, Martin H (2007) Calculations of steady and pulsating impinging jets - an assessment of 13 widely used turbulence models. Numerical Heat Transfer, Part B: Fundamentals 51(6):565-583. https://doi.org/10.1080/ 10407790701227328

66. Horrocks AR, Anand S (2016) Handbook of technical textiles. Volume 1: technical textile processes, 2. Ed. Woodhead, Duxford

67. Hrycak P, Lee DT, Gauntner JW, Livingood J. N. B. (1970) Experimental flow characteristics of a single turbulent jet impinging on a flat plate. Technical report (NASA-TN-D-5690, E-5239). https://ntrs.nasa.gov/archive/nasa/casi.ntrs.nasa.gov/ 19700011262.pdf. Accessed 17 May 2020

68. Ibarz A, Garza S, Pagán J (2008) Nonenzymatic browning of selected fruit juices affected by D-galacturonic acid. Int J Food Sci Technol 43(5):908-914. https://doi.org/10.1111/j.1365-2621. 2007.01541.x

69. Israelachvili JN (ed) (2011) Intermolecular and surface forces, 3rd edn. Burlington, Academic

70. Jensen B, Friis A (2005) Predicting the cleanability of mix-proof valves by use of wall shear stress. J Food Process Eng 28(2):89 106. https://doi.org/10.1111/j.1745-4530.2005.00370.x

71. Jullien C, Bénézech T, Carpentier B, Lebret V, Faille C (2003) Identification of surface characteristics relevant to the hygienic status of stainless steel for the food industry. J Food Eng 56(1): 77-87. https://doi.org/10.1016/S0260-8774(02)00150-4

72. Jurado E, Herrera-Márquez O, Plaza-Quevedo A, Vicaria JM (2015) Interaction between non-ionic surfactants and silica micro/nanoparticles. Influence on the cleaning of dried starch on steel surfaces. J Ind Eng Chem 21:1383-1388. https://doi.org/ 10.1016/j.jiec.2014.06.011

73. Jurado-Alameda E, Herrera-Márquez $\mathrm{O}$, Martínez-Gallegos JF, Vicaria JM (2015) Starch-soiled stainless steel cleaning using surfactants and $\alpha$-amylase. J Food Eng 160:56-64. https://doi.org/10. 1016/j.jfoodeng.2015.03.024

74. Kasemo B (2002) Biological surface science. Surf Sci 500(1-3): 656-677. https://doi.org/10.1016/S0039-6028(01)01809-X

75. Katsikogianni M, Missirlis YF (2004) Concise review of mechanisms of bacterial adhesion to biomaterials and of techniques used in estimating bacteria-material interactions. Eur Cells Mater 8(8): 37-57. https://doi.org/10.22203/eCM.v008a05

76. Katsikogianni MG, Missirlis YF (2010) Interactions of bacteria with specific biomaterial surface chemistries under flow conditions. Acta Biomater 6(3):1107-1118. https://doi.org/10.1016/j. actbio.2009.08.006

77. Khaldi M, Blanpain-Avet P, Guérin R, Ronse G, Bouvier L, André C, Bornaz S, Croguennec T, Jeantet R, Delaplace G (2015) Effect of calcium content and flow regime on whey protein fouling and cleaning in a plate heat exchanger. J Food Eng 147: 68-78. https://doi.org/10.1016/j.jfoodeng.2014.09.020

78. Khalid NI, Aziz NA, Nuraini AA, Taip FS, Anuar MS (2014) Alkaline cleaning-in-place of pink guava puree fouling deposit using lab-scale cleaning test rig. Agriculture and Agricultural Science Procedia 2:280-288. https://doi.org/10.1016/j.aaspro. 2014.11.040

79. Kidoaki S, Matsuda T (2002) Mechanistic aspects of protein/ material interactions probed by atomic force microscopy. Colloids Surf B: Biointerfaces 23(2-3):153-163. https://doi.org/ $10.1016 / \mathrm{S} 0927-7765(01) 00232-6$ 
80. Koglin B (1974) Systematik der Dispergiermittel. Chemie Ing Techn 46(17):720-726. https://doi.org/10.1002/cite.330461704

81. Koh E, Lee YT (2017) Antimicrobial activity and fouling resistance of a polyvinylidene fluoride (PVDF) hollow-fiber membrane. J Ind Eng Chem 47:260-271. https://doi.org/10.1016/j. jiec.2016.11.042

82. Kotsanopoulos KV, Arvanitoyannis IS (2015) Membrane processing technology in the food industry: food processing, wastewater treatment, and effects on physical, microbiological, organoleptic, and nutritional properties of foods. Crit Rev Food Sci Nutr 55(9):1147-1175. https://doi.org/10.1080/10408398.2012. 685992

83. Kraume M (2012) Transportvorgänge in der Verfahrenstechnik. Grundlagen und apparative Umsetzungen, 2. Ed. Springer-Verlag, Berlin, Heidelberg

84. Krupp H (1967) Particle adhesion: theory and experiment. Adv Colloid Interf Sci 1(2):111-239

85. Kühnl W (2011) Kolloidale Wechselwirkungen zwischen Proteinen im Zusammenspiel mit fluid-dynamischen Kräften an der Grenzfläche von Filtrationsmembranen. Gezeigt am Beispiel der Fraktionierung von Milchproteinen mittels Mikrofiltration. Dissertation Technische Universität München. VDI-Verlag, Düsseldorf

86. Kumar R, Ismail AF (2015) Fouling control on microfiltration/ ultrafiltration membranes: effects of morphology, hydrophilicity, and charge. J Appl Polym Sci 132(21). https://doi.org/10.1002/ app.42042

87. Kupetz M, Aumer J, Harms D, Zarnkow M, Sacher B, Becker T (2017) High-throughput $\beta$-glucan analyses and their relationship with beer filterability. Eur Food Res Technol 243(2):341-351. https://doi.org/10.1007/s00217-016-2748-3

88. Kurtz O, Meyer J, Kasper G (2016) Influence of filter operating parameters on fine dust emissions from pulse-cleaned filter bags. Chem Eng Technol 39(3):435-443. https://doi.org/10.1002/ceat. 201500340

89. Landau LD, Lifsic EM (1991) Hydrodynamik, 5th edn. Akademie, Berlin

90. Leach SJ, Walker GL, Smith AV, Farmer IW, Taylor G (1966) Some aspects of rock cutting by high speed water jets [and discussion]. Philos Trans R Soc A Math Phys Eng Sci 260(1110): 295-310. https://doi.org/10.1098/rsta.1966.0051

91. Lee JS, Seo JA, Lee HH, Jeong SK, Park HS, Min BR (2017) Simple method for preparing thin film composite polyamide nanofiltration membrane based on hydrophobic polyvinylidene fluoride support membrane. Thin Solid Films 624:136-143. https://doi.org/10.1016/j.tsf.2017.01.031

92. Leipert C, Nirschl H (2011) Untersuchung der Reinigungsfähigkeit von Filtergeweben aus Polymeren. Filtrieren und Separieren 25(5):270-277

93. Leipert C, Nirschl H (2012) Untersuchungen zum Reinigungsverhalten von Filtermedien mithilfe pulsatorischer Strömung. Chemie Ingenieur Technik 84(8):1285. https://doi. org/10.1002/cite. 201250370

94. Lifshitz EM, Hamermesh M (1956) The theory of molecular attractive forces between solids. Soviet Phys 2(1):73-83. https://doi. org/10.1016/B978-0-08-036364-6.50031-4

95. Lin T, Shen B, Chen W, Zhang X (2014) Interaction mechanisms associated with organic colloid fouling of ultrafiltration membrane in a drinking water treatment system. Desalination 332(1):100 108. https://doi.org/10.1016/j.desal.2013.11.001

96. Liu W, Fryer PJ, Zhang Z, Zhao Q, Liu Y (2006) Identification of cohesive and adhesive effects in the cleaning of food fouling deposits. Innovative Food Sci Emerg Technol 7(4):263-269. https:// doi.org/10.1016/j.ifset.2006.02.006

97. Löffler F, Dietrich H, Flatt W (eds) (1988) Dust collection with bag filters and envelope filters. Vieweg+Teubner, Wiesbaden
98. Luckert K(E) (2004) Handbuch der mechanischen Fest-FlüssigTrennung, 1st edn. Essen, Vulkan-Verlag

99. Marriott NG, Schilling W, Gravani RB (eds) (2018) Principles of food sanitation, 6th edn. New York, Springer

100. Martin H (1977) Heat and mass transfer between impinging gas jets and solid surfaces. Adv Heat Tran 13:1-60. https://doi.org/10. 1016/S0065-2717(08)70221-1

101. Mauermann M (2012) Methode zur Analyse von Reinigungsprozessen in nicht immergierten Systemen der Lebensmittelindustrie. Dissertation, Technische Universität Dresden

102. Mauermann M, Eschenhagen U, Bley T, Majschak J-P (2009) Surface modifications - application potential for the reduction of cleaning costs in the food processing industry. Trends Food Sci Technol 20:S9-S15. https://doi.org/10.1016/j.tifs.2009.01.020

103. Miao M, Xin JH (2017) Engineering of high-performance textiles, 1st edn. Woodhead, Duxford

104. Middlewood PG, Carson JK (2012) Extraction of amaranth starch from an aqueous medium using microfiltration. Membrane fouling and cleaning. J Membr Sci 411-412:22-29. https://doi.org/10. 1016/j.memsci.2012.04.008

105. Milchers W (2001) Abtrag von Polymeren mit dem reinen Wasserstrahl. Dissertation Universität Hannover. Bericht aus dem Institut für Werkstoffkunde, Universität Hannover, vol 639. VDI-Verl., Düsseldorf

106. Moeller R-S (2018) Haftkräfte, Alterung und Überwachung funktionaler Oberflächen - Gärtücher im Gebrauch. Dissertation, Karlsruhe Institute of Technology

107. Moeller R-S, Nirschl H (2018) Optical dirt detection for a demand-controlled cleaning of woven filter cloth. Sep Purif Technol 207:336-343. https://doi.org/10.1016/j.seppur.2018.06. 058

108. Moriarty TF, Poulsson AHC, Rochford ETJ, Richards RG (2015) Bacterial adhesion and biomaterial surfaces. Comprehensive Biomater 4:75-100. https://doi.org/10.1016/B978-0-08-0552941.00007-6

109. Morra M, Cassinelli C (1998) Bacterial adhesion to polymer surfaces. A critical review of surface thermodynamic approaches. J Biomater Sci Polym Ed 9(1):55-74. https://doi.org/10.1163/ $156856297 X 00263$

110. Mulugeta E, Geyer M (2005) Characterising the washing processes of vegetables and potatoes. Biosyst Eng 91(4):441-453. https:// doi.org/10.1016/j.biosystemseng.2005.05.009

111. Nakamura M, Hori N, Ando H, Namba S, Toyama T, Nishimiya N, Yamashita K (2016) Surface free energy predominates in cell adhesion to hydroxyapatite through wettability. Mater Sci Eng C Mater Biol Appl 62:283-292. https://doi.org/10.1016/j.msec. 2016.01.037

112. Narziß L, Back W (2008) Abriss der Bierbrauerei, 7th edn. Wiley$\mathrm{VCH}$, Weinheim

113. Nassauer J, Kessler HG (1985) Einfluß elektrostatischer Vorgänge auf die Reinigung von Oberflächen. Chemie Ingenieur Technik 57(3):235-236. https://doi.org/10.1002/cite.330570309

114. Nerín C, Aznar M, Carrizo D (2016) Food contamination during food process. Trends Food Sci Technol 48:63-68. https://doi.org/ 10.1016/j.tifs.2015.12.004

115. Neugrodda C, Gastl M, Becker T (2015) Comparison of foam analysis methods and the impact of beer components on foam stability. J Am Soc Brew Chem 73(2):170-178. https://doi.org/ 10.1094/ASBCJ-2015-0129-01a

116. Nguyen T, Roddick FA, Fan L (2012) Biofouling of water treatment membranes: a review of the underlying causes, monitoring techniques and control measures. Membranes 2(4):804-840. https://doi.org/10.3390/membranes2040804

117. Noh H, Vogler EA (2006) Volumetric interpretation of protein adsorption: mass and energy balance for albumin adsorption to 
particulate adsorbents with incrementally increasing hydrophilicity. Biomaterials 27(34):5801-5812. https://doi.org/10.1016/j. biomaterials.2006.08.005

118. Oertel H, Böhle M, Reviol T (2015) Strömungsmechanik. Für Ingenieure und Naturwissenschaftler, 7th edn. Springer, Wiesbaden

119. Ohnesorge WV (1936) Die Bildung von Tropfen an Düsen und die Auflösung flüssiger Strahlen. J Appl Math Mech 16(6):355358. https://doi.org/10.1002/zamm.19360160611

120. Olsen HS, Falholt P (1998) The role of enzymes in modern detergency. J Surfactant Deterg 1(4):555-567. https://doi.org/10.1007/ s11743-998-0058-7

121. Or CM, Lam KM, Liu P (2011) Potential core lengths of round jets in stagnant and moving environments. J Hydro Environ Res 5(2): 81-91. https://doi.org/10.1016/j.jher.2011.01.002

122. Otto C, Zahn S, Hauschild M, Babick F, Rohm H (2016) Comparative cleaning tests with modified protein and starch residues. J Food Eng 178:145-150. https://doi.org/10.1016/j. jfoodeng.2016.01.015

123. Otto C, Zahn S, Plenker J, Rohm H (2014) Application of a flow cell for the comparative investigation of the cleaning behavior of starch and protein. J Food Eng 131:1-6. https://doi.org/10.1016/j. jfoodeng.2014.01.008

124. Otto C, Zahn S, Rost F, Zahn P, Jaros D, Rohm H (2011) Physical methods for cleaning and disinfection of surfaces. Food Eng Rev 3(3-4):171-188. https://doi.org/10.1007/s12393-011-9038-4

125. Palabiyik I, Yilmaz MT, Fryer PJ, Robbins PT, Toker OS (2015) Minimising the environmental footprint of industrial-scaled cleaning processes by optimisation of a novel clean-in-place system protocol. J Clean Prod 108:1009-1018. https://doi.org/10. 1016/j.jclepro.2015.07.114

126. Park J-A, Kim S-B (2015) DLVO and XDLVO calculations for bacteriophage MS2 adhesion to iron oxide particles. J Contam Hydrol 181:131-140. https://doi.org/10.1016/j.jconhyd.2015.01. 005

127. Petrus H, Li H, Chen V, Norazman N (2008) Enzymatic cleaning of ultrafiltration membranes fouled by protein mixture solutions. J Membr Sci 325(2):783-792. https://doi.org/10.1016/j.memsci. 2008.09.004

128. Pope SB (2015) Turbulent flows, 2nd edn. Cambridge University Press, Cambridge

129. Prieto NE, Lilienthal W, Tortorici PL (1996) Correlation between spray cleaning detergency and dynamic surface tension of nonionic surfactants. J Am Oil Chem Soc 73(1):9-13. https://doi.org/10. 1007/BF02523441

130. Purchas DB, Sutherland K (2002) Handbook of filter media, 2nd edn. Elsevier Science, Oxford

131. Quadt T, Schmidt E (2012) Untersuchungen zur Haftkraftberechnung bei der Partikelablösung in der Querstromfiltration. Filtrieren und Separieren 26(3):175-181

132. Rabinovich YI, Adler JJ, Ata A, Singh RK, Moudgil BM (2000a) Adhesion between nanoscale rough surfaces: I. Role of asperity geometry. J Colloid Interface Sci 232(1):10-16. https://doi.org/10. 1006/jcis.2000.7167

133. Rabinovich YI, Adler JJ, Ata A, Singh RK, Moudgil BM (2000b) Adhesion between nanoscale rough surfaces: II. Measurement and comparison with theory. J Colloid Interface Sci 232(1):17-24. https://doi.org/10.1006/jcis.2000.7168

134. Rahimpour A, Madaeni SS (2010) Improvement of performance and surface properties of nano-porous polyethersulfone (PES) membrane using hydrophilic monomers as additives in the casting solution. J Membr Sci 360(1-2):371-379. https://doi.org/10.1016/ j.memsci.2010.05.036

135. Ravereau J, Fabre A, Brehant A, Bonnard R, Sollogoub C, Verdu J (2016) Ageing of polyvinylidene fluoride hollow fiber membranes in sodium hypochlorite solutions. J Membr Sci 505: 174-184. https://doi.org/10.1016/j.memsci.2015.12.063

136. Reh A, Plank B, Kastner J, Gröller E, Heinzl C (2012) Porosity maps - interactive exploration and visual analysis of porosity in carbon fiber reinforced polymers. Computer Graphics Forum 31(3):1185-1194. https://doi.org/10.1111/j.1467-8659.2012. 03111.x

137. Reynolds O (1883) An experimental investigation of the circumstances which determine whether the motion of water shall be direct or sinuous, and of the law of resistance in parallel channels. Philos Trans R Soc Lond 174(224-226):84-99. https://doi.org/10. 1098/rstl.1883.0029

138. Rieger H, Piesche M (2013) CFD-Simulation zur Berechnung der durch Gewebestrukturen induzierten Strömungsfelder mithilfe der Immersed-boundary-Methode. Chemie Ingenieur Technik 85(12): 1921-1927. https://doi.org/10.1002/cite.201300001

139. RIWETA 4.2 (2020a) Polyamid 6 (PA6). http://www.kern.de/de/ technisches-datenblatt/polyamid-pa-6?n=1102 1. Accessed 16 May 2020

140. RIWETA 4.2 (2020b) Polybutylenterephthalat (PBT). http:// www.kern.de/de/technisches-datenblatt/polybutylenterephthalatpbt?n=1311_1. Accessed 16 May 2020

141. RIWETA 4.2 (2020c) Polyethersulfon (PES). http://www.kern.de/ cgi-bin/riweta.cgi?lng=1\&nr=2441. Accessed 16 May 2020

142. RIWETA 4.2 (2020d) Polyethylentherephtalat (PET). http://www. kern.de/de/technisches-datenblatt/polyethylenterephthalat-pet?n= 1301_1. Accessed 16 May 2020

143. RIWETA 4.2 (2020e) Polytetrafluorethylen (PTFE). http://www. kern.de/de/technisches-datenblatt/polytetrafluorethylen-ptfe?n= 1601_1. Accessed 16 May 2020

144. Rumpf H (1974) Die Wissenschaft des Agglomerierens. Chemie Ingenieur Technik 46(1):1-46. https://doi.org/10.1002/cite. 330460102

145. Rushton A, Ward AS, Holdich RG (1999) Solid-liquid filtration and separation technology. Wiley-VCH, Weinheim

146. Schlichting H, Krause E (2006) Grenzschicht-Theorie, 0th edn. Springer, Berlin

147. Schmidt RH, Rodrick GE (2003) Food safety handbook. Wiley, Hoboken, N.J.

148. Schubert H (1982) Kapillarität in porösen Feststoffsystemen. Springer, Berlin

149. Schwegmann H, Ruppert J, Frimmel FH (2013) Influence of the $\mathrm{pH}$-value on the photocatalytic disinfection of bacteria with $\mathrm{TiO} 2$ explanation by DLVO and XDLVO theory. Water Res 47(4): 1503-1511. https://doi.org/10.1016/j.watres.2012.11.030

150. Sharma PK, Hanumantha Rao K (2003) Adhesion of Paenibacillus polymyxa on chalcopyrite and pyrite: surface thermodynamics and extended DLVO theory. Colloids Surf B: Biointerfaces 29(1):21-38. https://doi.org/10.1016/S09277765(02)00180-7

151. Siebert KJ, Lynn PY (1997) Haze-active protein and polyphenols in apple juice assessed by turbidimetry. J Food Sci 62(1):79-84. https://doi.org/10.1111/j.1365-2621.1997.tb04372.x

152. Siekmann HE, Thamsen PU (2009) Strömungslehre für den Maschinenbau. In: Technik und Beispiele, 2nd edn. Springer, Berlin

153. Sigloch H (2017) Technische Fluidmechanik, Oth edn. Springer, Berlin

154. Spurk JH, Aksel N (2010) Strömungslehre. Einführung in die Theorie der Strömungen, 8th edn. Springer, Berlin

155. Stahl S, Leipert C, Nirschl H (2013) The cleanability of particle loaded woven filter media in solid-liquid separation. Sep Purif Technol 110:196-201. https://doi.org/10.1016/j.seppur.2013.02. 003

156. Stahl S, Siggelkow S, Nirschl H (2007) A microbiological test method to determine the cleanability of filter media in solid- 
liquid-separation applications. Eng Life Sci 7(2):136-142. https:// doi.org/10.1002/elsc.200620183

157. Stanga M (ed) (2010) Sanitation, Cleaning and disinfection in the food industry, 1st edn. Weinheim, Ed. Wiley-VCH

158. Stieß M (ed) (2009) Mechanische Verfahrenstechnik Partikeltechnologie 1, 3rd edn. Berlin, Springer

159. Stokes GG (1845) On the theories of internal friction of fluids in motion. Transactions of the Cambridge Philosophical Society (8): 287-305

160. Tamime AY (ed) (2008) Cleaning-in place: dairy, food and beverage operations, 3rd edn. Oxford, Wiley-Blackwell

161. Tang G, Chen Y, Silaen AK, Krotov Y, Riley MF, Zhou CQ (2019a) Investigation on coherent jet potential core length in an electric arc furnace. Steel Research International 90(4): Publication: 1800381 1-9. Doi: https://doi.org/10.1002/srin. 201800381

162. Tang G, Chen Y, Silaen AK, Wang T, Zhou CQ (2019b) Investigation of supersonic oxygen jet potential core length at various ambient temperatures. JOM 71(2):633-643. https://doi. org/10.1007/s11837-018-3244-y

163. Tani I, Komatsu Y (1966) Impingement of a round jet on a flat surface. Proceedings of the Eleventh International Congress of Applied Mechanics:672-676. https://doi.org/10.1007/978-3-66229364-5 88

164. Templin BR, Leith D (1988) Effect of operating conditions on pressure drop in a pulse-jet cleaned fabric filter. Plant/Operations Progress 7(4):215-222. https://doi.org/10.1002/prsb.720070404

165. Tien C (2012) Principles of filtration, 1st edn. Elsevier, Boston

166. Ulmer MU (2014) Analyse der Reinigung von Sieb- und Filtergeweben im Querstrom mit Hilfe der Gesetze des Stoffübergangs. Dissertation, Technische Universität München

167. Valentas KJ (1997) Handbook of food engineering practice. CRC, Boca Raton

168. van Oss CJ (ed) (2006) Interfacial forces in aqueous media, 2nd edn. Boca Raton, CRC

169. van Oss CJ (2007) Development and applications of the interfacial tension between water and organic or biological surfaces. Colloids Surf B: Biointerfaces 54(1):2-9. https://doi.org/10.1016/j. colsurfb.2006.05.024

170. Verwey EJW, Overbeek JTG (1947) Theory of the stability of lyophobic colloids. J Phys Colloid Chem 51(3):631-636. https:// doi.org/10.1021/j150453a001

171. Visser J (1972) On Hamaker constants. A comparison between Hamaker constants and Lifshitz-van der Waals constants. Adv Colloid Interf Sci 3(4):331-363. https://doi.org/10.1016/00018686(72)85001-2

172. Visser J (1989) Van der Waals and other cohesive forces affecting powder fluidization. Powder Technol 58(1):1-10. https://doi.org/ 10.1016/0032-5910(89)80001-4

173. Weidemann C (2014) Reinigungsfähigkeit mithilfe kontinuierlicher und pulsierender Strömung. Dissertation, Karlsruhe Institute of Technology
174. Weidemann C, Vogt S, Nirschl H (2014) Cleaning of filter media by pulsed flow - establishment of dimensionless operation numbers describing the cleaning result. J Food Eng 132:29-38. https:// doi.org/10.1016/j.jfoodeng.2014.02.005

175. Weigl B (2003) Trennkräfte zwichen Mikroorganismen, Partikeln und Oberflächen. Dissertation, Technische Universität München

176. Werner R, Bollwein B, Petersen R, Tippmann J, Becker T (2016) Pulsatile jet cleaning of filter cloths contaminated with yeast cells. Chem Eng Technol. https://doi.org/10.1002/ceat.201600049

177. Wildbrett G (ed) (2006) Reinigung und Desinfektion in der Lebensmittelindustrie, 2nd edn. Hamburg, Behr

178. Wilson DI, Le BL, Dao HDA, Lai KY, Morison KR, Davidson JF (2012) Surface flow and drainage films created by horizontal impinging liquid jets. Chem Eng Sci 68(1):449-460. https://doi.org/ 10.1016/j.ces.2011.10.003

179. Wu W, Giese RF, van Oss CJ (1999) Stability versus flocculation of particle suspensions in water - correlation with the extended DLVO approach for aqueous systems, compared with classical DLVO theory. Colloids Surf B: Biointerfaces 14(1-4):47-55. https://doi.org/10.1016/S0927-7765(99)00023-5

180. Xing J, Ni Q-Q, Deng B, Liu Q (2016) Morphology and properties of polyphenylene sulfide (PPS)/polyvinylidene fluoride (PVDF) polymer alloys by melt blending. Compos Sci Technol 134:184190. https://doi.org/10.1016/j.compscitech.2016.08.020

181. Xu L-C, Logan BE (2005) Interaction forces between colloids and protein-coated surfaces measured using an atomic force microscope. Environ Sci Technol 39(10):3592-3600. https://doi.org/ 10.1021/es048377i

182. Xu L-C, Siedlecki CA (2007) Effects of surface wettability and contact time on protein adhesion to biomaterial surfaces. Biomaterials 28(22):3273-3283. https://doi.org/10.1016/j. biomaterials.2007.03.032

183. Yang J, Bhagat RK, Fernandes RR, Nordkvist M, Gernaey KV, Krühne U, Wilson DI (2019) Cleaning of toothpaste from vessel walls by impinging liquid jets and their falling films: quantitative modelling of soaking effects. Chem Eng Sci 208:115148. https:// doi.org/10.1016/j.ces.2019.08.006

184. Yousaf MS, Yusof S, Bin Abdul Manap MY, Abd-Aziz S (2010) Storage stability of clarified banana juice fortified with inulin and oligofructose. J Food Process Preserv 34:599-610. https://doi.org/ 10.1111/j.1745-4549.2009.00419.x

185. Zhang X, Wang H, Liu Z, Zhu Y, Wu S, Wang C, Zhu Y (2017) Fabrication of durable fluorine-free superhydrophobic polyethersulfone (PES) composite coating enhanced by assembled MMTSiO2 nanoparticles. Appl Surf Sci 396:1580-1588. https://doi.org/ 10.1016/j.apsusc.2016.11.217

186. Zuki FM (2012) The use of XDLVO theory in the prediction of adhesion of Pseudomonas putida to mineral surfaces. Dissertation, University of Sheffield

Publisher's Note Springer Nature remains neutral with regard to jurisdictional claims in published maps and institutional affiliations. 